\title{
An assemblage of lizards from the Early Cretaceous of Japan
}

\author{
Susan E. Evans and Ryoko Matsumoto
}

\begin{abstract}
The Early Cretaceous deposits of the Tetori Group of western Japan have yielded a diverse wetland vertebrate fauna including both aquatic and terrestrial components. The latter include several lizards, three of which have been named and described in detail: Kaganaias hakusanensis, a long-bodied aquatic lizard; Kuwajimalla kagaensis, a herbivorous borioteiioid; and Sakurasaurus shokawensis, a relative of the Chinese Jehol genus Yabeinosaurus. Here we describe lizard material from the Shiramine locality representing five or six additional taxa, three of which are named herein: a small lizard represented by two associations, but of unresolved phylogenetic position; a slightly larger lizard with tricuspid teeth that is related to borioteiioids; and a bizarre lizard with bicuspid teeth represented by a single, but morphologically unique, jaw. The three additional lizard morphotypes are unnamed. One has bicuspid teeth but unspecialised jaws. The second has small unicuspid teeth in a dentary bearing a deep coronoid process and resembling the dentary of the enigmatic Late Cretaceous Mongolian Myrmecodaptria microphagosa. The third morphotype is represented by a single fragmentary specimen and has small teeth in a deep jaw. Together, the Kuwajima lizards form a phylogenetically and morphologically diverse assemblage.
\end{abstract}

Susan E. Evans. Department of Cell and Developmental Biology, University College London, Gower Street, London WC1E 6BT, UK. ucgasue@ucl.ac.uk (corresponding author)

Ryoko Matsumoto. Kanagawa Prefecture Museum of Natural History, 499 Iryuuda, Odawara, Kanagawa Prefecture, 250-0035, Japan. ryokosaur@gmail.com

Keywords: Squamata; new genus; new species; Japan; Asia; Cretaceous

Submission: 18 October 2014. Acceptance: 8 July 2015

\section{INTRODUCTION}

In the Early Cretaceous, Japan lay on the edge of the main Asian landmass, adjacent to what is now the Korean Peninsula, and therefore relatively close to the deposits of the Chinese Yixian and Jiufotang formations that have yielded the exceptional Jehol Biota (Chang et al., 2003). Although fossil remains from Japan are generally less complete than specimens from China, deposits of the Tetori Group have yielded a rich and diverse vertebrate assemblage that combines aquatic and terrestrial components including fish

http://zoobank.org/FB40EDBC-4B8B-4E0F-857E-C5AE6CC78C5A

Evans, Susan E. and Matsumoto, Ryoko. 2015. An assemblage of lizards from the Early Cretaceous of Japan. Palaeontologia Electronica 18.2.36A: 1-36

palaeo-electronica.org/content/2015/1271-japanese-fossil-lizards

Copyright: Palaeontological Association July 2015 


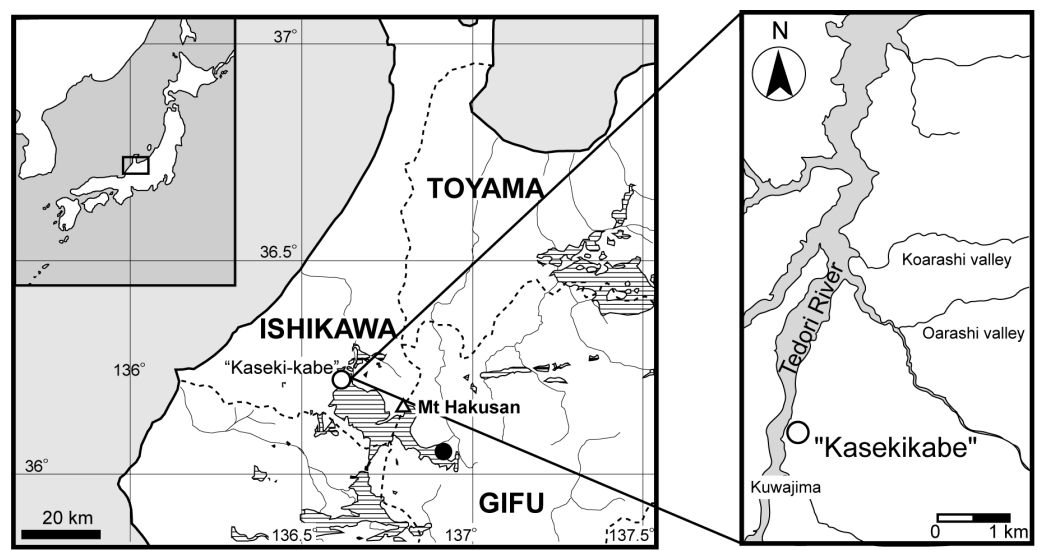

FIGURE 1. Map showing the location of the Kaseki-Kabe fossil site, Ishikawa Prefecture.

(Yabumoto, 2000), rare amphibians (Evans and Manabe, 1998; Matsuoka, 2000a), synapsids (mammals and tritylodonts) (Setoguchi et al., 1999a, 1999b; Manabe et al., 2000a; Matsuoka, 2000b; Takada et al., 2001; Rougier et al., 2007), turtles (Hirayama, 1996, 1999, 2000), choristoderes (Evans and Manabe, 1999a; Matsumoto et al., 2002, 2007, 2014), pterosaurs (Unwin et al., 1996, 1997; Unwin and Matsuoka, 2000), non-avian dinosaurs (Azuma and Tomida, 1995; Hasegawa et al.,1995; Manabe, 1999; Manabe and Barrett, 2000; Manabe et al., 2000b), birds (Unwin and Matsuoka, 2000), and squamates (Evans and Manabe, 1999b, 2000, 2008, 2009; Evans et al., 1998, 2006).

Most of the small tetrapods described from the Tetori Group were recovered from one of two localities: Shokawa, Takayama City, Gifu Prefecture, and Shiramine, Hakusan City, Ishikawa Prefecture. However, other localities have been reported. Shikama (1969) briefly described an articulated skeleton from Fukui Prefecture, which he interpreted as a lizard and named Tedorosaurus asuwaensis. This specimen is in a private collection and is inaccessible, leaving its identification uncertain. The lizard species Sakurasaurus shokawensis was first described from Shokawa (Evans and Manabe, 1999b), and the same locality has yielded more fragmentary remains of one or more additional lizard taxa. More recently, squamate remains have also been recovered from the slightly younger (early Albian) Sasayama Group of Hyogo Prefecture (Ikeda and Saegusa, 2013; Ikeda et al., 2015). Shiramine has been more productive, with a diverse squamate assemblage (Evans and Manabe, 2000) that includes Sakurasaurus sp. (Evans and Manabe, 2009); a long- bodied aquatic lizard (Kaganaias hakusanensis, Evans et al., 2006); an herbivorous borioteiioid (Kuwajimalla kagaensis, Evans and Manabe, 2008), and several smaller taxa. The latter are described herein.

\section{Geological Setting}

Rocks of the Tetori Group outcrop in Central Honshu, Japan (Maeda, 1961; Matsukawa and Obata, 1994; Kusuhashi et al., 2002; Fujita, 2003; Isaji et al., 2005), and are represented by the Kuzuryu, Itoshiro, and Akaiwa Subgroups in ascending order (Maeda, 1961). All the fossil material described in this paper came from the upper part of the Kuwajima Formation, Itoshiro Subgroup, at a single locality, the Kaseki-kabe or "Fossil-cliff", in the village of Shiramine, Hakusan City, Ishikawa Prefecture (Figure 1). In earlier accounts, these deposits were dated variously as Kimmeridgian to Hauterivian (Matsukawa and Obata, 1994), early Neocomian (Kusuhashi et al., 2002), Valanginian (Isaji et al., 2005), and late Hauterivian (Fujita, 2003). The latter age estimate ( 132 Ma, Gradstein and Ogg, 2004) was based on the finding of a Hauterivian ammonite in a marine horizon (Kamihambara Formation) in the central part of the Itoshiro Subgroup at another locality. This date was in agreement with Zircon fission-track dates of $135 \pm 7 \mathrm{Ma}$ for the laterally equivalent (Maeda, 1961) Okuradani Formation at Shokawa, Gifu Prefecture (Gifu-ken Dinosaur Research Group, 1992). A Berriasian to Hauterivian age for the Kuwajima Formation was also supported by a Middle to Late Jurassic (Callovian-Oxfordian) age for the underlying Kuzuryu Subgroup (based on ammonites), and a Barremian (or late Hauterivian) to Aptian age for the overlying Akaiwa Subgroup 
(based on non-marine molluscs, pollen and spore assemblages, and Zircon fission-track dates, Matsukawa and Obata, 1994; Fujita, 2003; Isaji et al., 2005). If correct, the fossil vertebrates from the Kuwajima Formation would have been slightly older ( 10 million years) than specimens from the Yixian Formation of China. However, Kusuhashi et al. (2006) reported zircon U-Pb ages of $132.9 \pm 0.9$ Ma and $117.5 \pm 0.7 \mathrm{Ma}$ for the Okuradani Formation, and concluded the deposits correlated to the Barremian-Aptian. More recently, Sha and Hirano (2012) placed the Okuradani Formation (and therefore its lateral equivalent, the Kuwajima Formation) in the Aptian (117.5 $\pm 0.7 \mathrm{Ma})$. Overall, there remains a degree of uncertainty as to the age of the Kuwajima Formation, but most recent analyses place it within the Barremian-Aptian interval, and it is therefore probably close in age to the Chinese Yixian and Jiufotang Formations of China (Chang et al., 2009).

In the Kaseki-Kabe, the Kuwajima Formation is represented by alternating beds of sandstones and mudstones with three dominant facies (Isaji et al., 2005), each representing a different palaeoenvironment with its own taphonomic characteristics and assemblage. Facies 1 (peat marsh) and Facies 2 (shallow lake) yield a vertebrate assemblage dominated by freshwater aquatic taxa (fish, turtles, and choristoderes). Facies 3 has been interpreted as representing a vegetated subaerial swamp environment, subject to occasional flooding (Isaji et al., 2005). This facies has produced most of the terrestrial vertebrate remains (tritylodonts, mammals, lizards, dinosaurs).

\section{MATERIALS AND METHODS}

The fossiliferous deposits were extracted in bulk $\left(\sim 16,700 \mathrm{~m}^{3}\right)$ during the construction of a road tunnel through the fossil cliff in 1997. Of this material, a sample of $210 \mathrm{~m}^{3}$ of facies 2 and 3 was retained and examined. As the matrix is acid resistant, each block has to be broken into manageable pieces, examined for traces of bone, and then prepared manually. This delicate and time-consuming process is still ongoing but has yielded over 2,000 catalogued vertebrate specimens. Of these specimens, more than 270 have been attributed to lizards, including many isolated elements (jaws, vertebrae, osteoderms) but also one articulated partial skeleton (the holotype of Kaganaias, Evans et al., 2006) and several associations. In some of the latter, the bones are jumbled together and have the appearance of either oral or faecal pellets, possibly of one of the contemporaneous theropod dinosaurs (Azuma and Tomida, 1995; Manabe, 1999; Manabe and Barrett, 2000).

Specimens were photographed using a Nikon D800 digital camera and drawn under a Wild binocular microscope with drawing tube. Selected specimens were also subjected to X-ray microtomography using a TESCO, Microforcus CT TXS 320-ACTIS machine, at $312 \mathrm{kv}, 202 \mu \mathrm{A}$. However, the images from CT scanning yielded little useful information.

In order to determine the phylogenetic position of the more complete specimens, we ran phylogenetic analyses using the morphological matrix of Gauthier et al. (2012), as revised and extended by Longrich et al. (2012: 622 characters, 221 species [219 originals + two from Japan]). The specimens were coded based on detailed examination of the original specimens (Appendix 1 and Appendix 2). In many cases, individual elements are preserved at an angle to the rock surface and although we have tried as far as possible to illustrate them in a planar view, it was not always possible. This should be borne in mind when trying to code characters based only on the two dimensional figures. We designated the basal rhynchocephalian Gephyrosaurus bridensis as outgroup taxon rather than the more derived Sphenodon punctatus (as used by Gauthier et al., 2012). An exhaustive search was performed (unordered, equally weighted, unconstrained) using a protocol in which the command 'xmult' is employed to find the shortest tree (MPT) 50 times independently (Daza et al., 2013). In this protocol, each run of xmult, TBR (20 independent Wagner trees) is followed by sectorial searching, ratchet and tree drifting [100 iterations], and then, for each set of five trees obtained, tree fusion (Goloboff, 1999). The 50 resulting MPTs are then subjected to further TBR branch swapping to find additional collapsible branches, until 1000 MPTs are recovered. Tree support is estimated using Bremer support indices (Bremer, 1994), jackknifing, and symmetric resampling (expressed as $\mathrm{GC}$ values reflecting difference in frequencies for groups supported/contradicted; Goloboff et al., 2003), and values plotted on the strict consensus tree.

However, the above analysis did not include the character ordering used by Gauthier et al. (2012). Moreover, all recent molecular phylogenies differ significantly from those based on morphological characters, notably in the placement of iguanians and gekkotans. For that reason, we ran a series of additional analyses with varying protocols. All analyses were run using TNT New Tech- 
nology search with Sectorial search, Ratchet (20 iterations), and Tree Fusion, set at 1000 Random Addition Sequences. Separate runs were made with characters unordered and then with characters ordered according to Gauthier et al. (2012) and Longrich et al. (2012). In each case (ordered or unordered), the analyses were run both equally weighted and with Goloboff's implied weighting $(\mathrm{k}=3,7,15$, and 30$)$, which down weights homoplastic characters (Goloboff et al., 2008). All analyses were then repeated using a molecular backbone constraints tree (Wiens et al., 2010; Pyron et al., 2013): (Gekkota, Dibamidae (Scincoidea [Xantusiidae, Cordylidae, Scincidae] (Lacertoidea [Teiidae+Gymnophthalmidae, Lacertidae+ Amphisbaenia] (Iguania, Anguimorpha, Serpentes)). In total, 27 taxa were included in the constraint tree as follows: Gekkota (Gekko gecko, Eublepharis macularius, Lialis burtonensis), Dibamidae (Dibamus novaeguineae, Anelytropsis papillosus), Cordylidae (Cordylus mossambicus, Platysaurus imperator), Xantusiidae (Xantusia vigilis, Cricosaura typica), Scincidae (Acontias percivali, Scincus sp.), Teiidae (Tupinambis teguixin), Gymnophthalmidae (Pholidobolus montium), Lacertidae (Lacerta viridis, Takydromus ocellatus), Amphisbaenia (Bipes biporus, Rhineura floridana), Anguimorpha (Xenosaurus grandis, Anniella pulchra, Varanus salvator), Iguania (Anolis carolinensis, Oplurus cyclurus, Sauromalus ater, Calotes emma, Uromastyx aegypticus), Serpentes (Cylindrophis ruffus, Python molurus). All remaining taxa were allowed to float.

\section{Institutional and Anatomical Abbreviations}

SBEI, collection of the Shiramine Board of Education, Shiramine Institute of Paleontology, Hakusan City Board of Education, Hakusan, Japan (formerly Shiramine Village Board of Education, Shiramine, Japan). Shiramine specimens (SBEI) have a dual cataloguing system with a general collection number and also a taxonomic group collection number (e.g., Li=lizard). Thus, for example, SBEI 190 (Li1) was the first lizard specimen catalogued from the locality.

Art-Pa, articular-prearticular; a.tth, anteriormost tooth position; Cor.ft, coronoid facet; Fr, frontals; $\mathrm{Hy}$, hyoid ceratobranchial; II, ilium; ims, intramandibular septum; J, jugal; L.Cor, left coronoid; L.D, left dentary; L.Fe, left femur;L.Fi, left fibula; L.Fr, left frontal; L.J, left jugal; L.Mx, left maxilla; L.Pe, left pelvis; L.Pofr, left postorbitofrontal; L.Prf, left prefrontal; L.Ti, left tibia; Mx, maxillary facet; P, parietal; P.D, postdentary element; Ph, phalanx;
Po.ft, position of postorbital facet; Pofr.ft, position of postorbitofrontal facet; Px.Fe, proximal head of femur; Q, quadrate; R.An, right angular; R.Cor, right coronoid; R.D, right dentary; R.Fe, right femur; R.Fr, right frontal; R.J, right jugal; R.Mx, right maxilla; R.Pa, right prearticular; R.Pal, right palatine; R.Pofr, right postorbitofrontal; R.Pt, right pterygoid; R.Px, right premaxilla; R.Spl, right splenial; R.Su, right surangular; Sa.rb.ft, sacral rib facet; Sq.ft, squamosal facet; sym, symphysis; Vert, vertebra; zyg, zygosphene.

\section{SYSTEMATIC PALAEONTOLOGY}

There is currently a discordance between the interfamilial relationships of squamates as yielded by morphology based analysis (e.g., Estes et al., 1988; Conrad, 2008; Gauthier et al., 2012) and those using molecular data sets or combined evidence (e.g., Townsend et al., 2004; Vidal and Hedges, 2009; Wiens et al., 2006, 2010; Müller et al., 2011; Jones et al., 2013; Pyron et al., 2013). Most notably, molecular analyses have not supported the monophyly of several higher groups in widespread use since the work of Estes et al. (1988), notably Scleroglossa (all squamates except Iguania), Scincomorpha (lacertoids and scincoids), and Autarchoglossa (non-gekkotan, non-iguanian squamates). However, the following squamate clades are generally recovered by both molecular and morphological data sets: Iguania, Gekkota, Scincoidea, Anguimorpha, Serpentes, and Lacertoidea (sensu Pyron et al., 2013). The latter includes teiids, gymnophthalmids, lacertids, and, in molecular and combined evidence trees, amphisbaenians (e.g., Müller et al., 2011). The fossil group Borioteioiidea, encompassing the Asian gilmoreteiids (=macrocephalosaurs) and Euramerican polyglyphanodonts (sensu Nydam et al., 2007), is also included within Lacertoidea by some analyses (e.g., Nydam et al., 2007; Conrad, 2008), but not others (e.g., Gauthier et al., 2012; Longrich et al., 2012).

SQUAMATA Oppel, 1811 Family Indet.

Genus KUROYURIELLA gen. nov. zoobank.org/6609C8A9-B39E-4CF6-B676-9ABBF371BC0F

Type species. Kuroyuriella mikikoi

Etymology. From Kuro-yuri, the Black or Chocolate Lily that is the prefectural flower of Ishikawa

Diagnosis. As for type and only species

Kuroyuriella mikikoi sp. nov.

Figures 2.1-7, 3.1-9, 4.1-10 

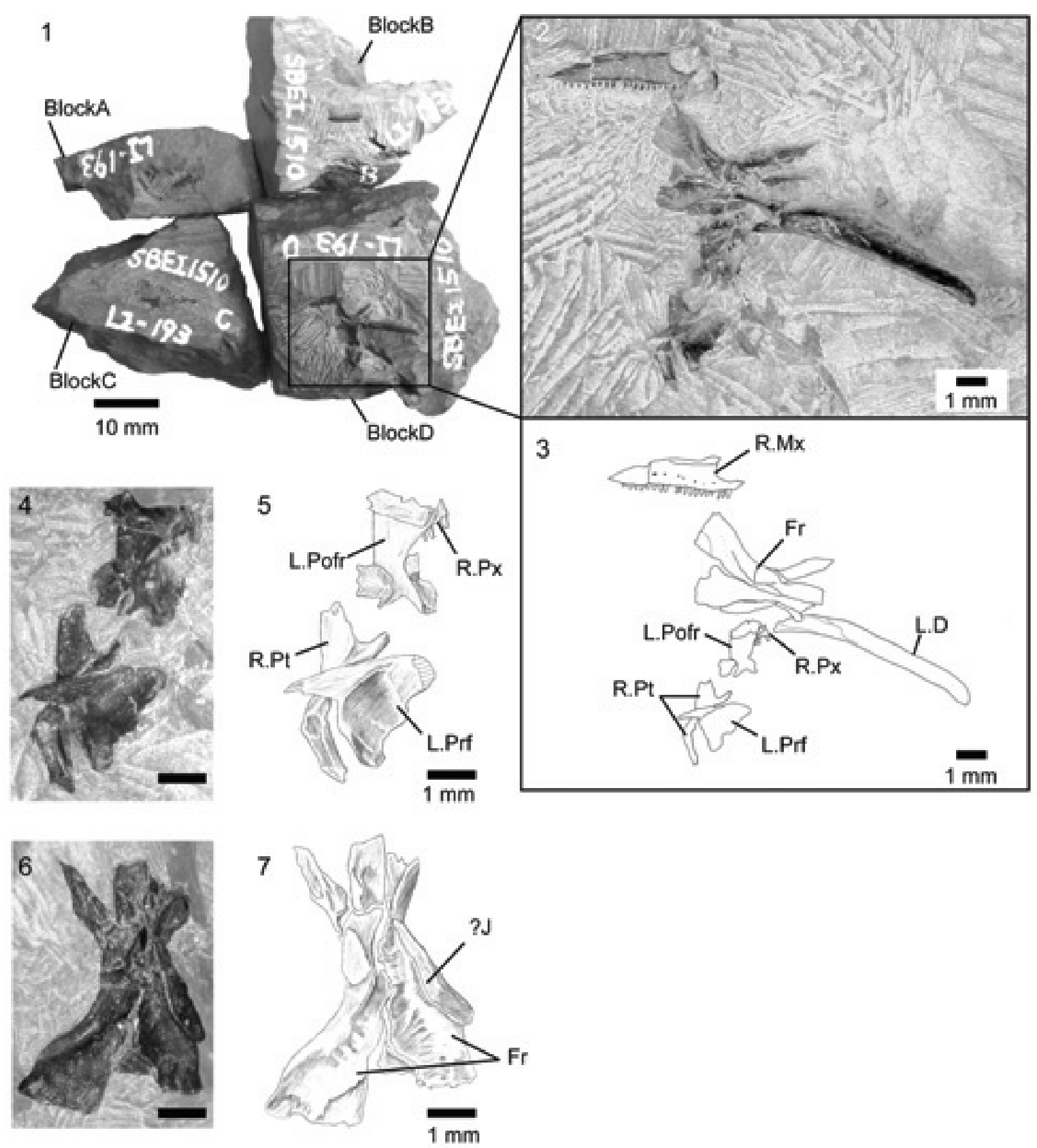

FIGURE 2. Kuroyuriella mikikoi gen. et sp. nov., holotype, SBEI 1510. 1, the four blocks making up the specimen; 2 3, the main association; 4-5, circumorbital bones, pterygoid and premaxilla; 6-7, frontal region in ventral view.

Etymology. For Mikiko Yamaguchi to recognise her technical skill in the preparation of the Kasekikabe fossil material over many years.

Holotype. SBEI 1510 (Li193), a disarticulated skull on four originally conjoined blocks (A- D) (Figure 2.1-7).

Type locality and horizon. Shiramine, Kuwajima district, Hakusan City, Ishikawa Prefecture, Japan.
Early Cretaceous Kuwajima Formation, Tetori Group.

Referred material. SBEI 1608 (Li223), an association on two small blocks (Figure 3.1-9).

Differential diagnosis. A small lizard that differs from contemporaneous Japanese Sakurasaurus shokawensis (Evans and Manabe, 1998, 2009) and Kuwajimalla kagaensis (Evans and Manabe, 

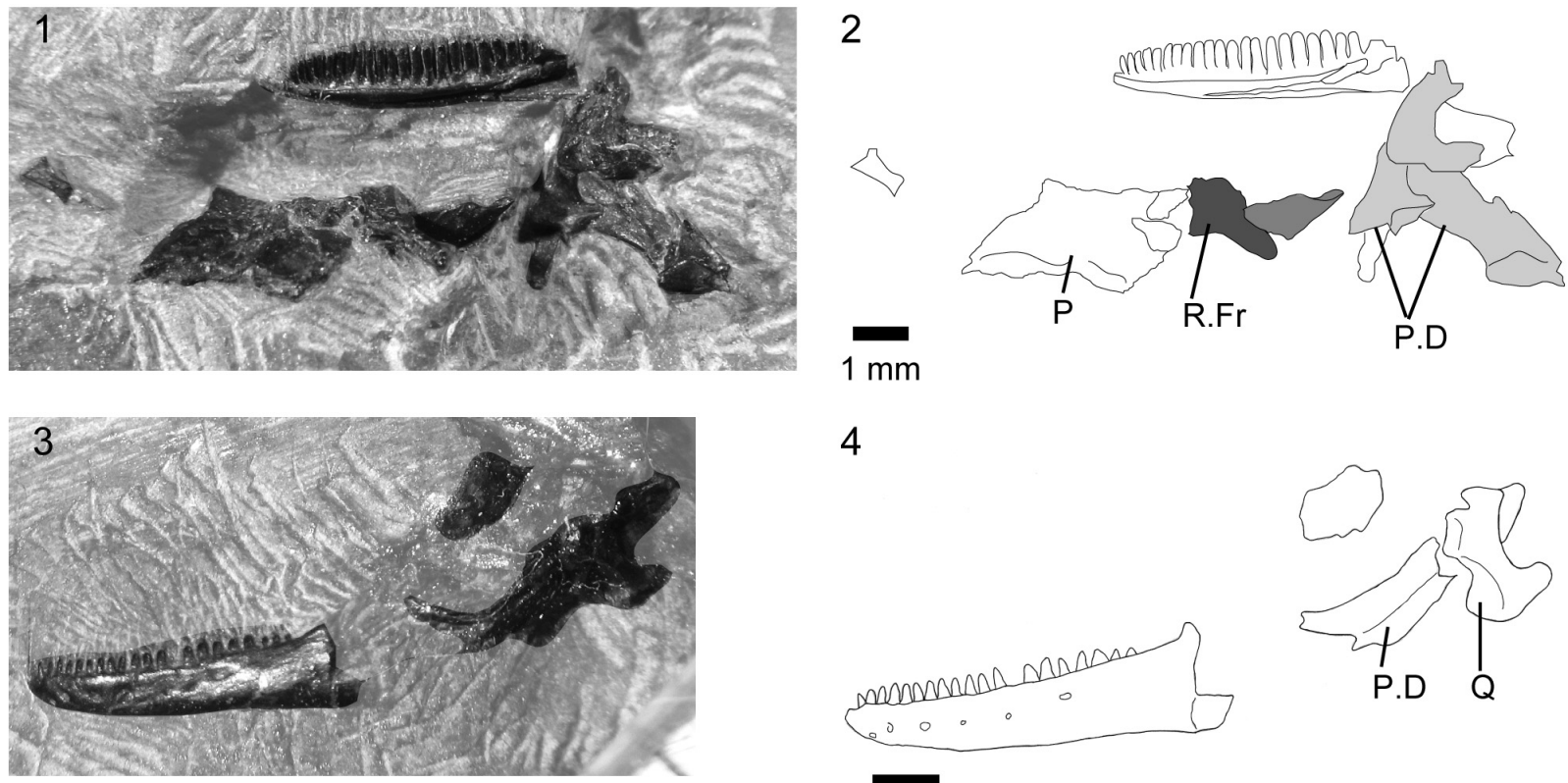

4
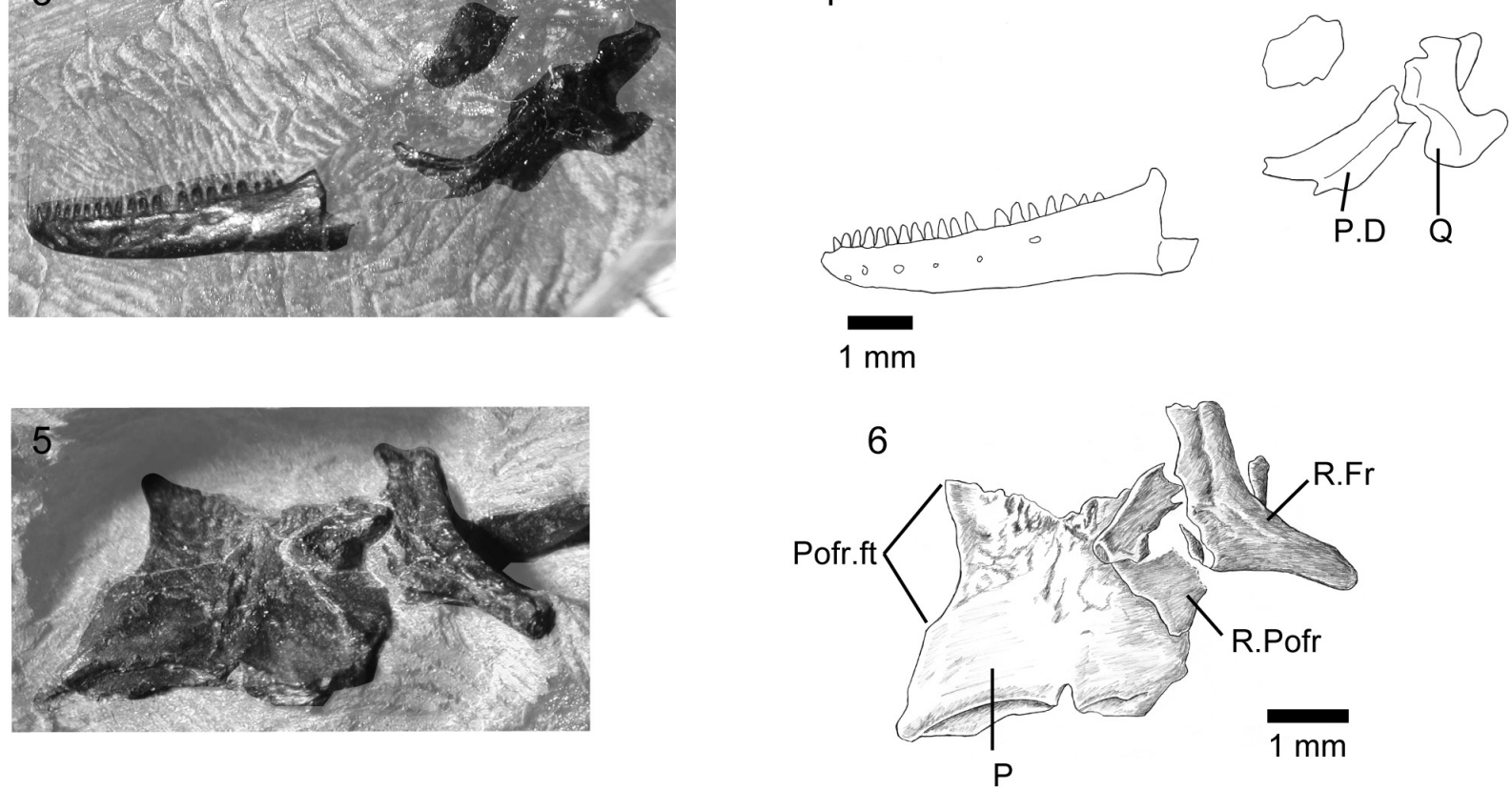

7

8
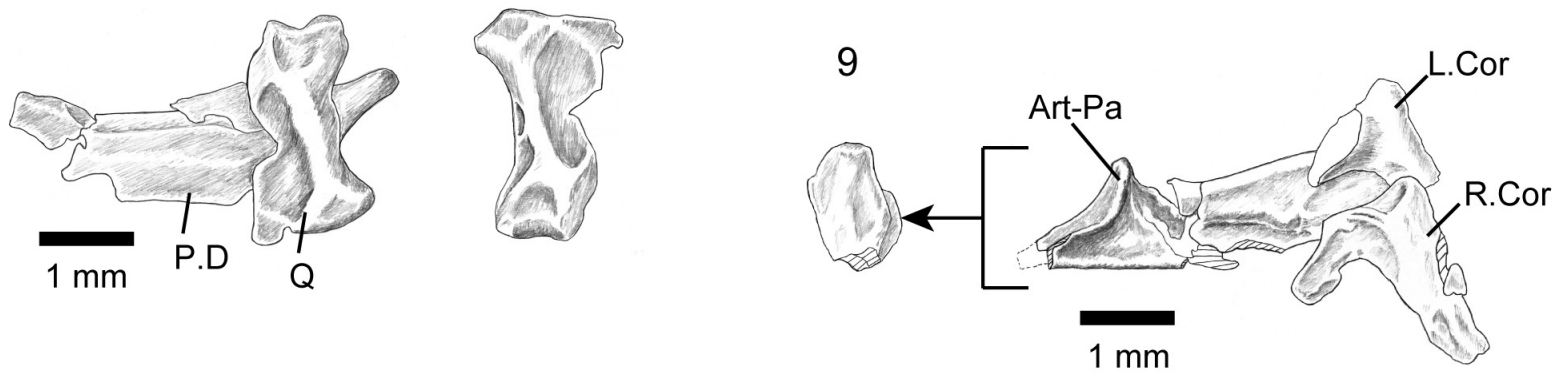

FIGURE 3. Kuroyuriella mikikoi gen. et sp. nov., referred specimen, SBEI 1608. 1-2, main association; 3-4, offset association; 5-6, detail of parietal and frontal; 7-8, detail of quadrate; 9, detail of postdentary bones. For abbreviations, see Material and Methods.

2008); Chinese Jehol Dalinghosaurus longidigitus (Ji and Ji, 2004; Evans and Wang, 2005), Liushusaurus acanthocaudata (Evans and Wang, 2010), and Yabeinosaurus tenuis (Evans et al., 2005; Evans and Wang, 2012; Wang and Evans, 2011); and from other known Jurassic and Early Cretaceous lizards (e.g., Euramerican Paramacel- lodus spp., Evans and Chure, 1998; Meyasaurus spp., Evans and Barbadillo, 1997) in the distinctive posterior margin of the dentary and strongly concave narial margin of maxilla; differs from Yabeinosaurus tenuis in parietal shape and in lacking parietal foramen; differs from Late Cretaceous Mongolian Slavoia darevskii (Alifanov, 2000a; Gao 
1
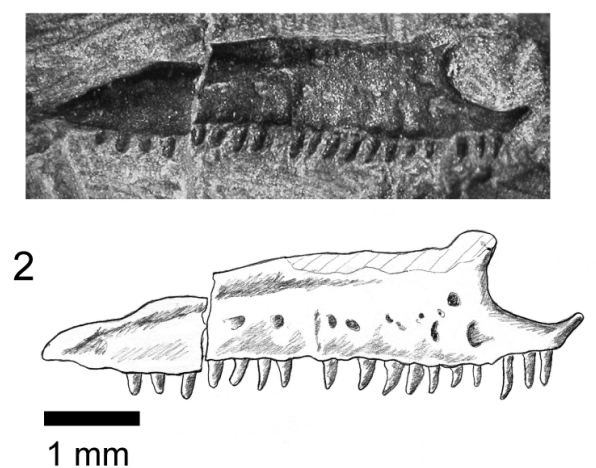

3

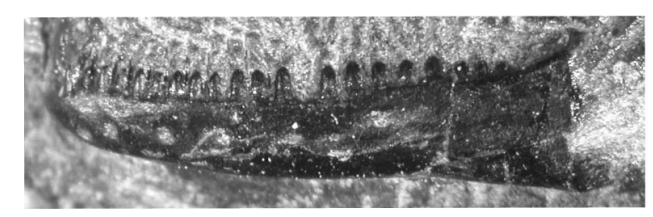

4

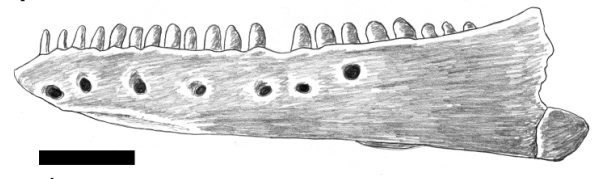

$1 \mathrm{~mm}$

5

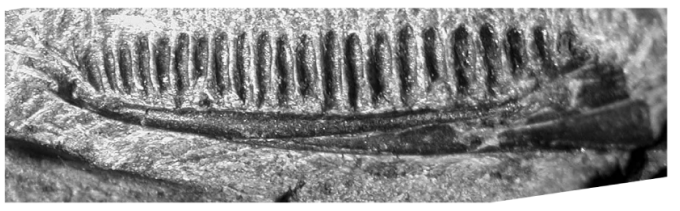

6

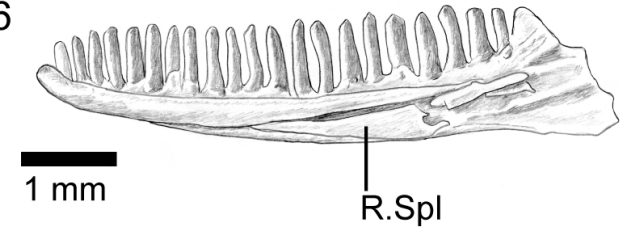

7
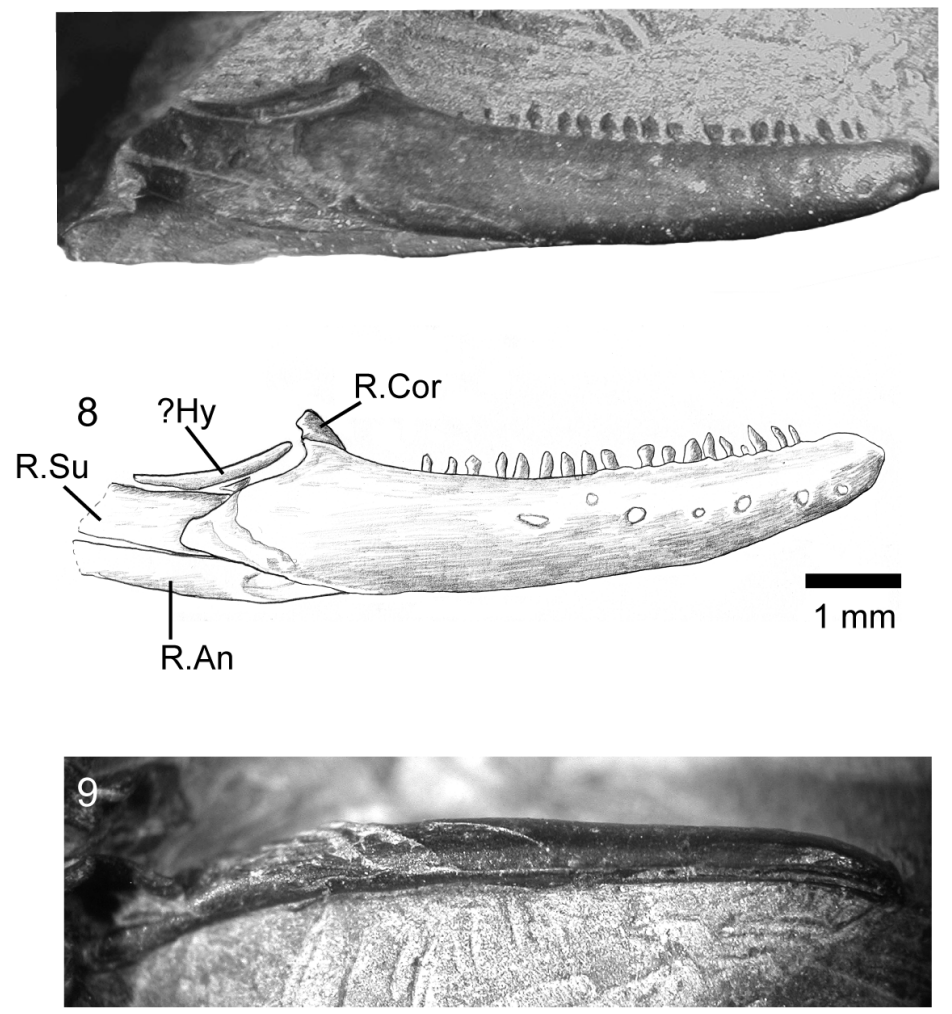

10

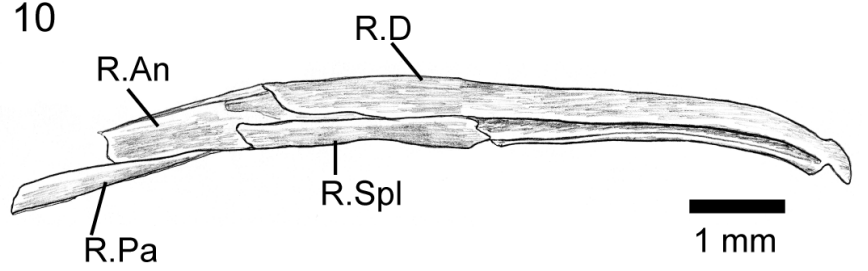

FIGURE 4. Kuroyuriella mikikoi gen. et sp. nov., jaw elements. 1-2, SBEI 1510, right maxilla in labial view; 3-4, SBEI 1608, left dentary in labial view; 5-6, SBEI 1608, right dentary in lingual view; 7-10, SBEI 1510, right mandible in 7-8, labial view, and 9-10, ventrolateral view. For abbreviations, see Material and Methods.

and Norell, 2000) in having proportionally more gracile jaw, proportionally longer and narrower frontals and parietals, and absence of parietal foramen; resembles the Late Cretaceous Carusia intermedia (Borsuk-Białynicka, 1985) and Exostinus serratus (Bhullar, 2010) in having frontals that are anteriorly narrow and posteriorly broad, with strong sub-olfactory processes, in the strong concavity of the maxillary narial margin, and, for Carusia but not Exostinus, in the shape of the dentary coronoid process, but Kuroyuriella differs from both in that the frontals are paired rather than fused and lack coarse tubercular sculpture, there is no sculpture on the maxilla, the parietal is of a different morphology (square and largely excluded from the upper temporal fenestra by postorbitofrontal facets, no parietal foramen) and sculpture pattern (low relief rather than coarse and tubercular); resembles Late Cretaceous genera Parmeosaurus scutatus and Hymenosaurus clarki (Gao and Norell, 2000) in gracile dentary with straight long axis, but differs from former in having uni- rather than tricuspid teeth, free posterior edge on dentary coronoid process, greater orbital emargination of frontals, 
deeply concave narial margin of maxilla, and in lacking cranial osteoderms. Hymenosaurus clarki is very poorly preserved, but as described, it differs from Kuroyuriella in having a prefrontal/postfrontal contact that excludes the short wide frontals from the orbital margin and a putative parietal foramen close to the posterior parietal margin.

Material. The holotype skull, SBEl 1510, was contained within a single block that was fragmented during preparation so that the bones are now spread over four smaller blocks (Figure 2.1) bearing: $A$, the orbital process of a left maxilla; $B$, an incomplete left dentary in labial view; $\mathrm{C}$, a right splenial; and $\mathrm{D}$, an association of right maxilla and premaxilla, right and left frontals, left prefrontal and postorbitofrontal, right pterygoid, and right mandible. The bones are mostly disarticulated but associated, suggesting some postmortem decay but little transport.

A second association (SBEI 1608) is attributed to Kuroyuriella mikikoi on the basis of dentary characters (tooth number and shape, curved free posterior edge), and complements the holotype in preserving the parietal, the dentary in lingual view, and more details of the accessory jaw bones (notably coronoids and articular). The specimen is on two blocks, also divided during preparation. Block $A$ bears the left dentary in labial view (Figure 3.3-4), as well as a poorly preserved elongate right postdentary mass and a right quadrate (Figure 3.7-8). Block B preserves the parietal and a partial frontal, as well as the right dentary, and postdentary bones including both coronoids, and the left surangular-angular-prearticular-articular association (Figure 3.1-2, 3.6, 3.9). No osteoderms are preserved in association with these specimens, nor are there isolated osteoderms of appropriate size on any of the many matrix samples from this locality.

The individual bones on both blocks are similar in size to comparable bones of extant lizards with an adult skull length of $\sim 10 \mathrm{~mm}$, a snout-vent length (SVL) of $45-50 \mathrm{~mm}$, and a total length of 110-125 mm. For their size, the skull bones are robust and fully ossified with weak sculpturing on the parietal and complex sutures, but given the disarticulation, the skeleton may have been that of a sub-adult.

Description. The holotype (SBEI 1510) preserves a right maxilla (5.8 $\mathrm{mm}$ long) in lateral view with 19 functional teeth and spaces for at least two more (Figures 2.3, 4.1-2). The bone is distinctive in having a strongly concave narial margin, caused partly by the dorsal curvature of the tip of the premaxillary process but also the anterior margin of the vertical facial process. Further posteriorly, the facial process is broken along its base, but the line of breakage clearly demarcates the original anteroposterior length. Posteriorly, the bone tapers into a rather short, suborbital process. The partial left maxilla (not figured) bears a medial shelf that supported the jugal, but the relative contributions of the two bones to the ventral orbital margin cannot be determined. A right premaxilla underlies the left postorbitofrontal (Figure 2.5). Three small teeth are visible with a gap representing a fourth tooth position. Further teeth may be hidden by the overlying element.

Paired frontals with deep subolfactory processes (=cristae cranii) that curve slightly inward and strong midline interdigitations are preserved in ventral aspect (Figure 2.6-7). They have separated slightly in the midline, and the right is twisted slightly on its long axis, making the anterior part of the bone appear somewhat narrower than it really is. Anteriorly each bone narrows into a straight edge that underlay the nasal. Posteriorly, both frontals bear ventrolateral and ventromedial parietal facets, suggesting the frontoparietal joint was inflexible rather than mesokinetic. The large prefrontal facet on the right bone is incised posteriorly but becomes shallower anteriorly. It extends roughly halfway along the bone. The prefrontal bone of that side is not preserved, but the left prefrontal has been displaced laterally and is preserved in medial view (Figure 2.4-5). Its frontal process is posteriorly tapered and relatively flat medially. The body is expanded and has a deeply concave medial surface. The posteroventral margin appears to bear a small facet, possibly for a lacrimal bone. Adjacent to the orbital edge of the left frontal in SBEI 1510 is a curved bar of bone with a mediolaterally compressed blade at one end and a thicker bar (rounded cross-section) at the other (Figure 2.6-7). This element may be part of a sickle-shaped jugal.

A near-complete left postfrontal or, more probably, postorbitofrontal (based on size and articulations) is preserved between the frontals and the pterygoid (Figure 2.4-5). It is roughly rectangular with a straight lateral margin and a more convex medial margin that would have clasped the frontoparietal suture (and matches the size and shape of the corresponding facet on the parietal of SBEI 1608 (see below) and the smaller shallow facet on the frontal of SBEI 1510. Judging from the arrangement of these bones, the jaw adductor muscles 
originated from the ventral surface of the parietal and postorbitofrontals.

SBEI 1510 preserves the only palatal element, a right pterygoid (Figure 2.4-5) with an anterior facet for the palatine and a sharply pointed lateral process bearing a narrow slot facet for the ectopterygoid. The posterior quadrate process is incomplete but it is narrow and shallow with a distinct dorsal pit (fossa columellae) for the epipterygoid flanked by a low crest that continues posteriorly along the dorsolateral edge of the bone.

An almost complete parietal is preserved on SBEI 1608 (Figure 3.5-6). The exposed dorsal surface bears weakly pustulate sculpture anteriorly, but is smooth posteriorly; it lacks any trace of head scale markings. The anterior margin (uppermost in Figure 3.5-6) is irregular rather than straight and a parietal foramen is not evident. The posterior margin bears shallow smooth nuchal shelves for neck muscle attachment, separated by a small median notch, probably for the processus ascendens of the supraoccipital. The postparietal (=supratemporal) processes are broken, revealing bases that are dorso-ventrally shallow in cross-section. On the right side, the parietal margin is partially overlain by a postorbitofrontal (Figure 3.5-6). On the left, the exposed margin is subdivided into a long anterior concavity that accommodated the postorbitofrontal and a shorter posterior edge that bordered a reduced upper temporal fenestra. Lateral to the right parietal margin, and displaced slightly posteriorly, is a partial right frontal, also lightly sculptured. On superficial examination, this element might be mistaken for an expanded jugal, but it lacks any of the requisite facets or thickenings. SBEI 1608 also preserves a right quadrate in association with the posterior end of the right mandible (Figure 3.7-8). It is small (2.3 mm tall) with a short lateral conch supported by a robust curved posterior pillar. The dorsal head is wider than the ventral one, the latter being anteroposteriorly short and weakly divided into medial and lateral condyles.

The lower jaw of Kuroyuriella mikikoi is represented on the holotype (SBEI 1510) by the left dentary and an almost complete right mandible, and on SBEI 1608 by right and left dentaries and parts of the postdentary series (Figure 4.3-10). The left dentary of SBEI 1510 (5.9 mm long, not figured) is preserved in labial view and is broken posterior to the tooth row. It bears 18 teeth with positions for two or three more in replacement and an edentulous region at the symphysial end that originally probably accommodated four or five small teeth. The right dentary $(7.4 \mathrm{~mm}$ long) is also preserved in labial view. It is slender with a rounded symphysial end and a subtle muscle attachment scar anteroventrally (Figure 4.7-10). The Meckelian fossa, exposed by preparation runs medially and then ventrally. At its posterior end, the dentary bears a small rounded coronoid process with a slightly recurved tip. From this tip, the edge of the dentary curves posteroventrally before extending into a process that meets the surangular. The tip of this surangular process and the posteroventral end of the dentary are damaged, but the bone clearly extended beyond the coronoid process to brace the postdentary bones. The posterodorsal dentary curvature appears to be a distinctive feature of Kuroyuriella mikikoi (resembling the condition in some acontine skinks, Evans, personal observation). A narrow, posteriorly angled coronoid bone projects above the dentary coronoid process. The surangular is relatively shallow throughout. A narrow rod of bone runs above it from the tip of the coronoid lappet. This rod cannot be part of the jaw and may be a displaced hyoid ceratobranchial, or possibly an epipterygoid. The relatively deep angular bears a shallow anterolateral facet for the posteroventral ramus of the dentary. The ventromedial surface of the mandible has been prepared (Figure 4.10). A small mylohyoid foramen perforates the angular just posterior to the level of the coronoid process. The angular met the splenial medially but its posterior limit is uncertain. The right splenial fills the Meckelian fossa posteriorly but terminates some distance from the symphysis, leaving the fossa open for about one-third of its length. The left splenial is preserved in isolation on SBEI 1510C (not figured). It is a relatively short bone with a blunt anterior margin. It fully encloses a small inferior alveolar foramen.

The jaw material of SBEI 1608 complements that of SBEI 1510. An almost complete left dentary (Figure 4.3-4) is preserved in labial view on Block $1608 \mathrm{~A}$. There is a posteroventral lappet (missing in SBEI 1510 although there is an impression for it on the angular). The dentary is $5.7 \mathrm{~mm}$ long parallel to its alveolar margin and $6.1 \mathrm{~mm}$ along the ventral edge. It is shallow with a relatively horizontal inferior margin, a tapering anterior end, and a conspicuous muscle scar along the anteroventral border. There are 21 teeth, with one space for a nonimplanted replacement. The labial surface is perforated by seven large, closely spaced neurovascular foramina. The right dentary (Figure 4.5-6) is in association with postdentary elements of both mandibles including the right and left coronoid, and the left surangular, articular and angular. It is pre- 
served in lingual view and displays a row of 21 closely packed teeth with no gaps for replacements, although several teeth bear small basal replacement pits. The teeth are narrow, straight, and unicuspid. The subdental ridge is shallow anteriorly and becomes more so posteriorly. The Meckelian fossa is medial for most of its length but it becomes ventromedial close to the level of tooth position five and is ventral at the symphysis. A splenial fills the posterior part of the Meckelian fossa for roughly one-third of its length. The coronoid process is preserved behind the last tooth and although there is some damage, part of a curved free posterior edge like that in SBEI 1510 is visible. The right coronoid has been displaced ventrally and is exposed in lateral aspect (Figure 3.9). It bears a small, posteriorly concave coronoid process and widely diverging anteroventral and posteroventral processes, of which the former is longer. The left coronoid is exposed in medial view in articulation with the surangular of that side. The latter element forms the lateral wall of a relatively large adductor fossa, the medial (prearticular) wall of which is largely broken away. The left articular is in situ. Its articular surface slopes posteroventrally but has an almost vertical anterior surface. In surface view (Figure 4.9), it is asymmetrical with an anteroposterior rather than mediolateral long axis. A weak ridge divides it into medial and lateral parts, with the lateral half widest anteriorly and narrowing posteriorly, but the medial half widest posteriorly and tapering anteriorly. The retroarticular process is broken but was narrow at its base.

Affinities. Together, SBEI 1510 and SBEI 1608, as type and referred specimen, characterise Kuroyuriella mikikoi as a small lizard having paired frontals with deep subolfactory processes; a median parietal without a parietal foramen, with sculpture of low relief, and with lateral shelves that restricted the adductor muscle origins to the ventral surface; upper temporal fenestrae that were at least partially closed by expanded postorbitofrontals; an unsculptured maxilla with a strongly concave narial margin; a large flared prefrontal; and a slender, relatively small pterygoid. In the shallow lower jaw, the teeth are closely packed, cylindrical, and pleurodont with lingual replacement; a subdental ridge is present; the dentary bears a tapering coronoid process that braces the coronoid, and has a posterior extension with a curved free margin; the surangular, angular, and splenial are all present and the surangular is shallow; the adductor fossa is open but not expanded; and the articular surface is asymmetrical.
The restricted upper temporal fenestra of Kuroyuriella mikikoi differs from the condition in iguanians, teiids, borioteiioids, or varanids where the fenestra is open and the jaw muscles extend onto the lateral and/or dorsal surfaces of the parietal. The dentary of Kuroyuriella lacks the closure of the Meckelian fossa found in all crown-group gekkotans, although the fossa remains open in the stem gekkotan Hoburogekko suchanovi (Daza et al., 2012). The small, closely packed homodont teeth and lingual replacement of Kuroyuriella mikikoi are unlike the teeth of extant anguimorphs but, again, are found in some fossil taxa (e.g., the Cretaceous Exostinus lancensis). Paired frontals, a reduced upper temporal fenestra, and a dentary coronoid process are found together in xantusiids, scincids, and cordyliforms (Scincoidea), but unlike many members of the latter two clades, neither SBEI 1510 nor 1608 shows any trace of cranial osteoderms. Skull material of Paramacellodus sp., a possible scincoid, from the Morrison Formation of North America (Late Jurassic, Evans and Chure, 1998) resembles Kuroyuriella mikikoi in having paired frontals and parietals with thin lateral margins (rather than vertical flanges for adductor muscle attachment) but differs in having separate postorbitals and postfrontals, without the embayment on the side of the parietal or the distinctive jaw morphology.

In order to explore the affinities of Kuroyuriella mikikoi, it was coded into the matrix of Gauthier et al. (2012), as extended by Longrich et al. (2012) (184 characters coded out of $622,70.4 \%$ missing data), and the analyses run as described above (Material and Methods). In both the unconstrained and constrained analyses, with and without character ordering, Kuroyuriella was placed on the squamate stem (Figures 5.1-2). However, with Implied Weighting activated $(k=3,7,15)$ to reduce the effect of homoplasy, Kuroyuriella moved into Scincoidea, to a position on the stem of Scincidae (Figures 6.1-2). With $\mathrm{k}=30$, Kuroyuriella returned to the stem-squamate position. The consistent placement of Kuroyuriella on the squamate stem is problematic and probably artifactual, but whether the weighted analysis is giving a more accurate placement is uncertain. Of the derived character states possessed by Kuroyuriella, 76 [1] (postorbital partly occludes upper temporal fenestra), 364 [1] (dentary coronoid process extends beyond level of coronoid apex), 367 [2] (coronoid process of dentary overlaps most of anterolateral surface of coronoid), and 369 [2] (dentary terminates well posterior to coronoid apex) provide some support for place- 

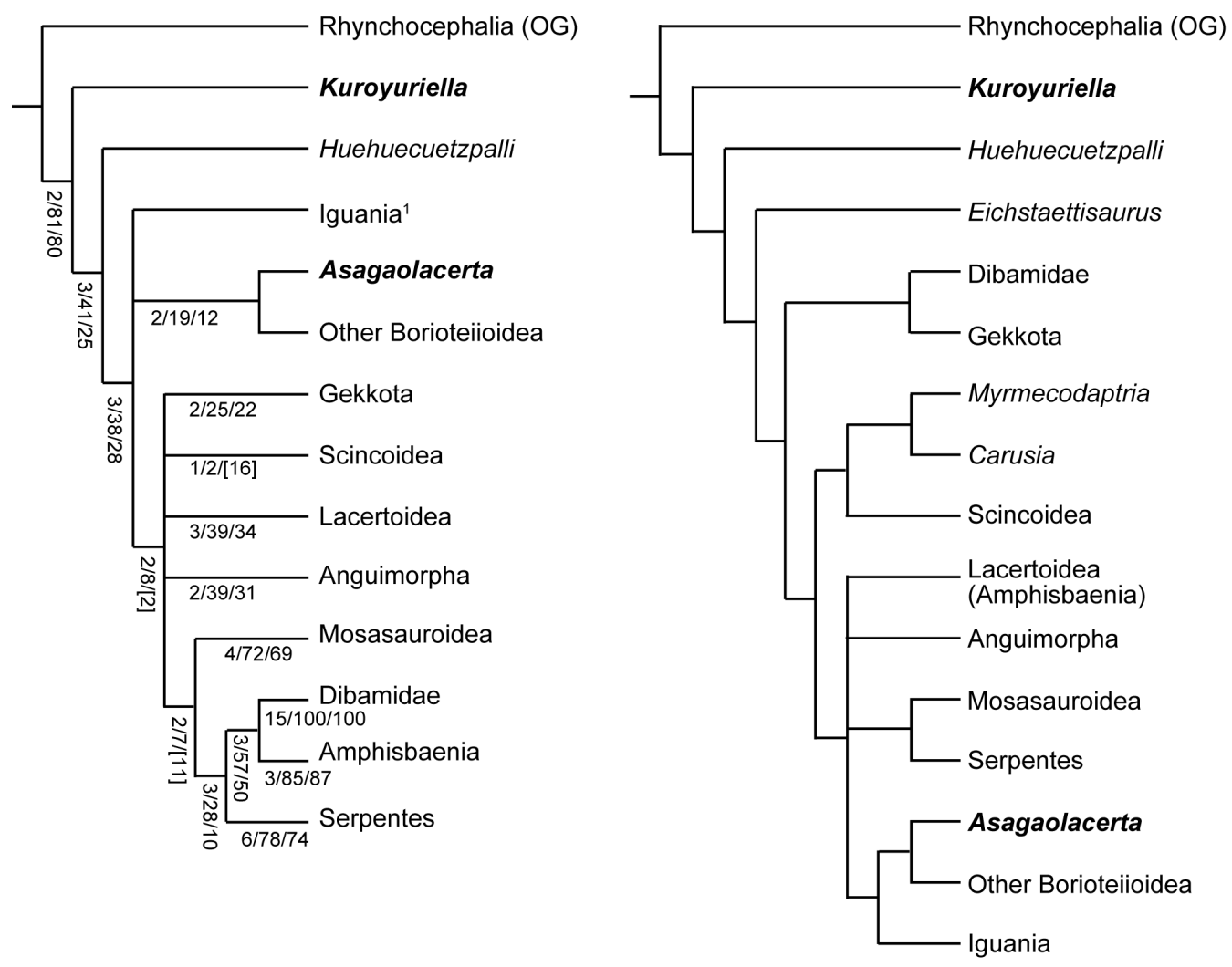

FIGURE 5. Phylogenetic position of Kuroyuriella mikikoi gen. et sp. nov. and Asagaolacerta tricuspidens gen. et sp. nov. in squamate trees, using the morphological data matrix of Gauthier et al. (2012), extended by Longrich et al. (2012). 1, Strict consensus of 1000 trees using unordered equally weighted characters, and run using TNT with 'minisearch.run'. Major clades are condensed. ${ }^{1}$ Note that Iguania was not monophyletic and comprised four smaller clades whose position was unresolved in relation to Borioteiioidea. Support values at nodes are Bremer/Jacknife/Symmetric resampling; 2, one of three trees (identical at this level) with clades condensed, run using the same matrix as in Figure 5.1 and analysed with TNT (with sectorial search, ratchet [20 iterations], and tree fusion all activated), but with the molecular tree of Wiens et al. (2010) and Pyron et al. (2013) providing the backbone constraint.

ment of Kuroyuriella on the stem of scincids, and 129 [1] (prefrontal extends to mid-orbit), 104 [1] (absence of parietal foramen) and 385 [1] (posterior mylohyoid foramen posterior to coronoid apex) would be consistent with that placement. However, given the considerable difference between the results using equal weighting and Implied Weighting, Kuroyuriella remains incertae sedis pending recovery of more complete material.

SQUAMATA Oppel, 1811 Family indet.

Genus ASAGAOLACERTA gen.nov. zoobank.org/4CF086BA-7B06-46A6-B8F2-D99F923B38B7

Type species. Asagaolacerta tricuspidens Etymology. From Asagao, the Japanese Morning Glory flower, the symbol of Hakusan City, Ishikawa Prefecture
Diagnosis. As for type and only species

$$
\begin{gathered}
\text { Asagaolacerta tricuspidens sp. nov. } \\
\text { Figures } 7-10
\end{gathered}
$$

zoobank.org/B80126CA-645A-44A8-A5D7-556512A4EF4B

Etymology. For the tricuspid teeth

Holotype. SBEI 1566 An association of skull, jaws and postcranial bones of a small lizard with facetted tricuspid teeth (Figure 7).

Type locality and horizon. The Kaseki-Kabe, Shiramine, Hakusan city, Ishikawa Prefecture, Japan. Early Cretaceous Kuwajima Formation, Tetori Group.

Referred material. Possibly SBEI 1621, a right maxilla (not figured).

Differential diagnosis. A small lizard characterised by the presence of sharply pointed tricuspid teeth with a central cusp and flanking anterior and 
1

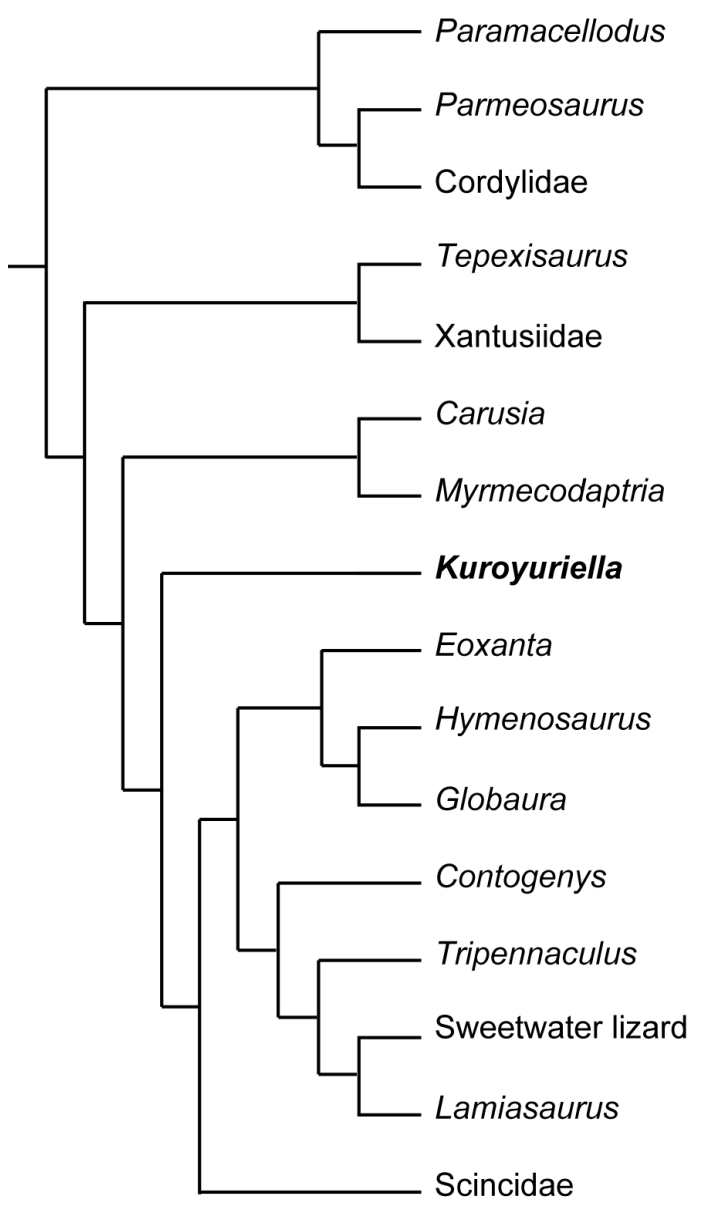

2

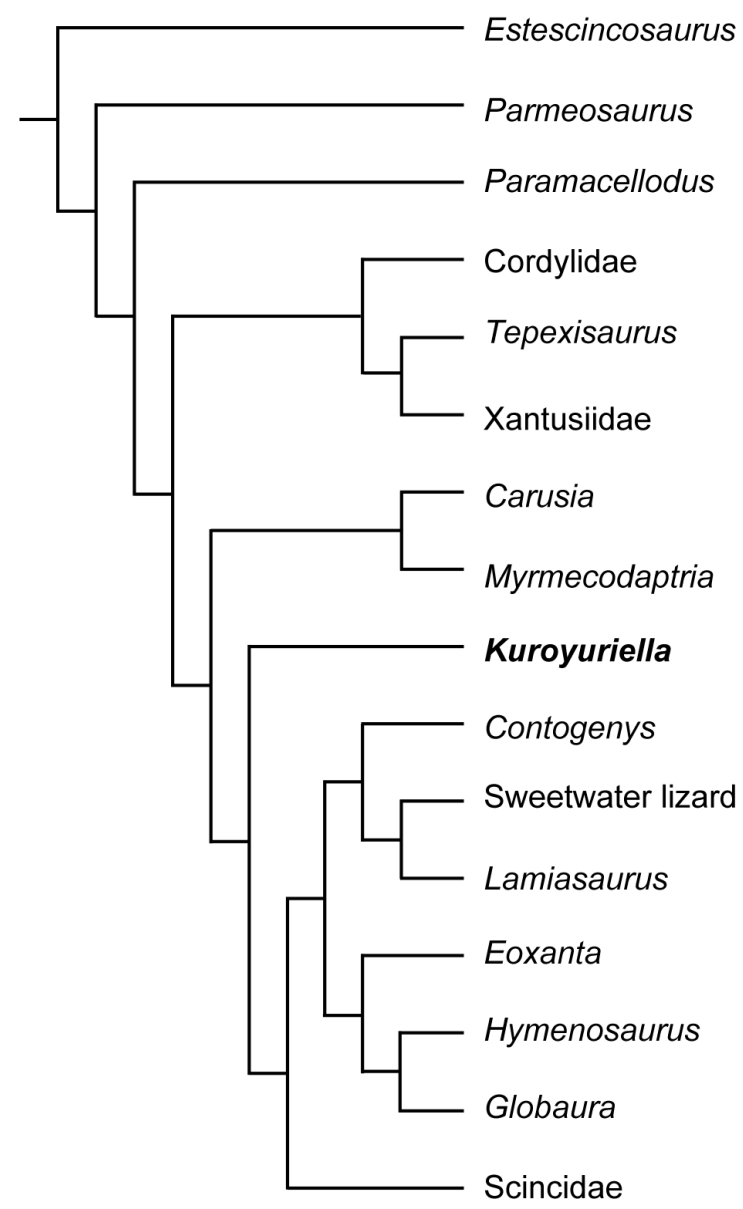

FIGURE 6. The phylogenetic position of Kuroyuriella mikikoi gen. et sp. nov. as recovered by analyses run with Implied Weighting ( $k=7$ ), and character ordering. 1, no backbone constraint; 2, backbone constraint tree based on the molecular trees of Wiens et al. (2010) and Pyron et al. (2013). Only the scincoid section of each tree is shown as in all analyses with equally weighted taxa, Kuroyuriella lies in the stem-squamate position shown in Figure 5.

posterior cuspules; tooth shaft cylindrical rather than bulbous, and tooth crown and shaft of similar width (not apically flared nor strongly labiolingually flattened). These dental features distinguish Asagaolacerta from other Kuwajima Formation lizards and from described Late Jurassic and Early Cretaceous taxa from Europe (e.g., Hoffstetter, 1967; Evans and Searle, 2002), North America (Nydam, 2002; Nydam and Cifelli, 2002a, 2002b), and China (Evans and Wang, 2005, 2010, 2012; Evans et al., 2005). Asagaolacerta tricuspidens resembles North American Late Cretaceous borioteiioids like Obamadon gracilis, Tripennaculus sp., Socognathus brachyodon and Chamops segnis (Longrich et al., 2012) in having tricuspid teeth, but differs in lacking any swelling of the tooth bases, and in having tooth crowns that are proportionally smaller in relation to the tooth bases.
Asagaolacerta tricuspidens also resembles Mongolian Late Cretaceous borioteiioid lizards (sensu Nydam et al., 2007) Altanteius facilis, Mongolochamops reshetovi, Pyramicephalosaurus cherminicus, and Tchingisaurus multivagus (Alifanov, 2000b; Gao and Norell, 2000) in having tricuspid teeth, and in having a slender jugal with long dorsal ramus forming most of posterior orbital border, but differs in having lower tooth count and step-like jugo-maxillary suture; further differs from Pyramicephalosaurus and Tchingisaurus in lacking any flaring or labiolingual flattening of tooth crowns (Alifanov, 2000b; Gao and Norell, 2000); resembles Late Cretaceous "mongolochamopine" Cyclurasia multidentata (Alifanov, 2000b) in jugo-maxillary suture shape but differs in having fewer, larger teeth. Asagaolacerta tricuspidens also differs from many Asian borioteiioids in lacking a hypertrophied 

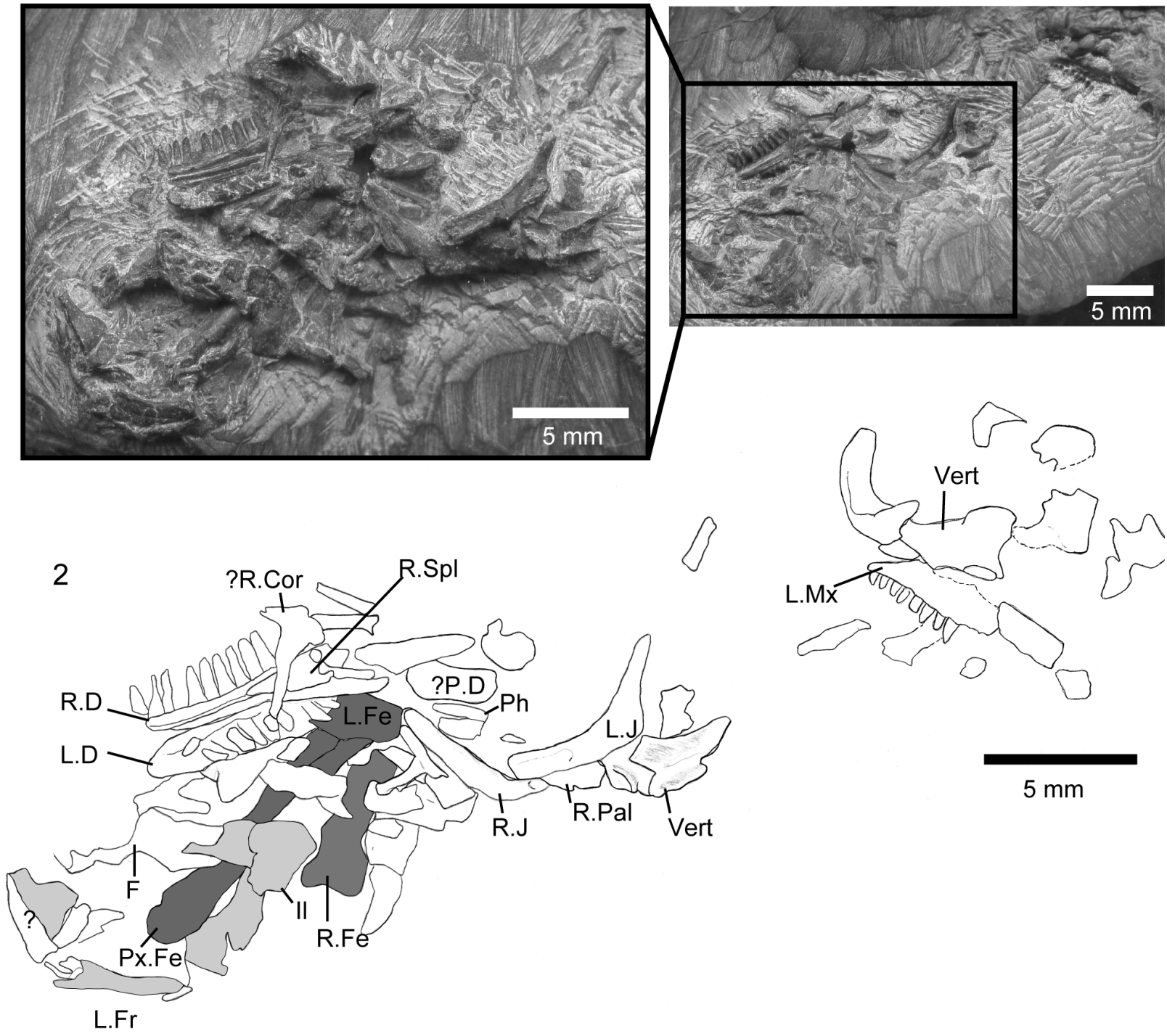

FIGURE 7. Asagaolacerta tricuspidens gen. et sp. nov., holotype, SBEI 1566. 1, the main association with the offset second bone group in the smaller image; 2, explanatory drawing of the same. For abbreviations, see Material and Methods.

splenial and build-up of cementum around tooth bases.

Material. SBEI 1566 (Figure 7) is a small block in which cranial and postcranial elements are superimposed, possibly as an oral pellet, but the specimen appears to represent a single individual (on the basis of non-repetition of parts and consistent size). Of the skull, the elements exposed include the left maxilla, the right and left dentaries and some postdentary bones, the left and right jugal, a partial left frontal, a palatine, and a quadrate, as well as some undetermined elements. The postcranial bones include several vertebrae, parts of the left pelvis, both femora, and scattered phalanges. The pectoral girdle and forelimbs seem to be missing. X-ray microtomography of the block revealed no other significant elements and no associated osteoderms. In comparison with modern skeletal material, the size of the jaws, pelvis, and limb elements are matched by a specimen of the extant teiid lizard Aspidoscelis tigris of $90 \mathrm{~mm}$ SVL (total length $290 \mathrm{~mm}$ ). The body proportions of Asagaolacerta tricuspidens, at least for those elements preserved, seem to have been broadly similar to the proportions of the living species. 
1

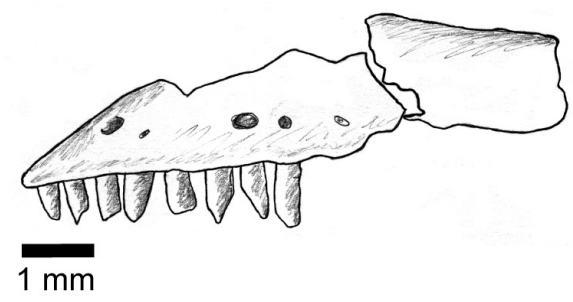

2

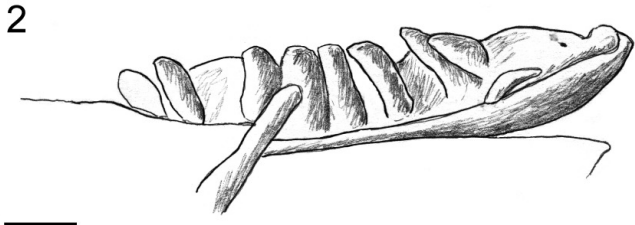

$1 \mathrm{~mm}$

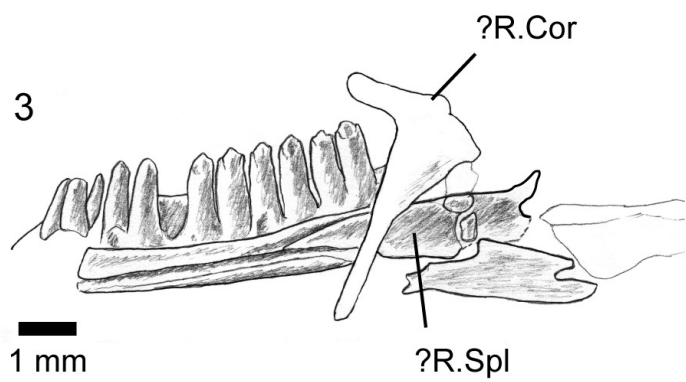

4

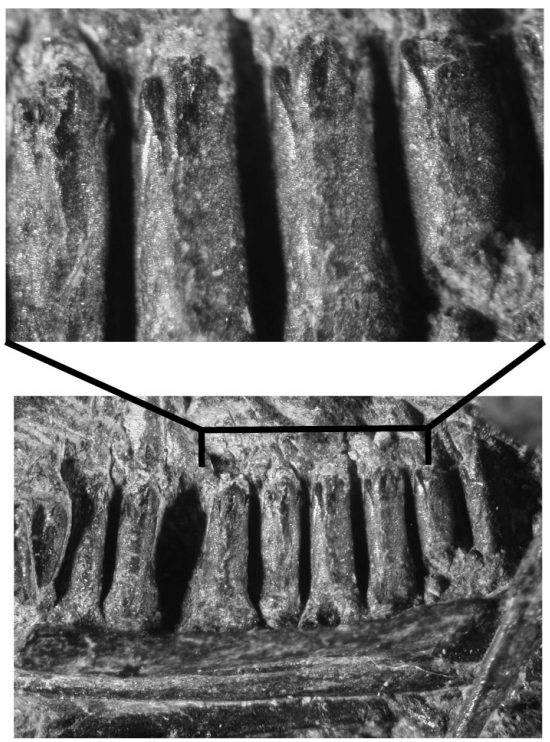

FIGURE 8. Asagaolacerta tricuspidens gen. et sp. nov., holotype, SBEI 1566. 1, Left partial maxilla in labial view; 2, left dentary in lingual view; $\mathbf{3}$, right dentary in lingual view; 4, details of teeth on the right dentary (enlarged from 3). For abbreviations, see Material and Methods.
Description. The anterior end of the left maxilla is exposed in labial view (Figure 8.1). The narial margin is oblique (unlike the deeper concavity of Kuroyuriella mikikoi). As preserved, the first eight teeth are slender and gradually increase in length, but the crowns are damaged, and it is not possible to determine whether there was a change from unicuspid to tricuspid within this series.

Of the other clearly identifiable skull elements, the right and left jugals lie together near the lower jaws (Figure 9.1-3). They are roughly L-shaped, but with an oblique angle between the ventral and postorbital rami. The left bone preserves a nearly complete ventral ramus and part of the postorbital ramus, whereas the right preserves most of the postorbital ramus and the ventral ramus, but the latter is overlain by a left palatine. The left ventral ramus bears an elongate lateral facet for the maxilla and was clearly partially overlapped by that bone in its anterior half, leaving a thin strip of the jugal along the ventral margin of the orbit. This arrangement would have given the jugal-maxillary suture a step-like structure in lateral view. It also suggests that the suborbital ramus of the maxilla extended only to mid-orbit. The jugal lacks a posterior spur or tubercle, but the thin bone is drawn into a slight angle. The postorbital ramus is slender and longer than the ventral ramus. The facet for the postorbital (or postorbitofrontal) is confined to the dorsal tip, suggesting that the jugal formed most of the posterior orbital margin and that the postorbital itself was not large. This interpretation is supported by a slight recess on the posterodorsal edge of the jugal that may have received the anterior tip of the squamosal, excluding the postorbital from the margin of the lower temporal fenestra.

Part of a left frontal is preserved in dorsal view at the edge of the association (Figure 7.2), but shows only that the frontals were paired and weakly sculptured with fine lines. A partial left palatine overlaps the ventral ramus of the right jugal. It is preserved in dorsal view and shows only that a foramen perforated the base of the maxillary process, as it does in most lizards. A robust curved bone close to the anterior end of the maxilla is identified as the right quadrate (Figure 9.4-5). It has a narrow conch and a posteriorly extended head, but no obvious notch or pit for the squamosal.

Both dentaries are preserved in association, the right in lingual view, the left in dorsolingual view (Figures 7, 8.2-3). The right shows 12 tooth positions with space for at least three further small teeth in the symphysial region. The tooth row is 

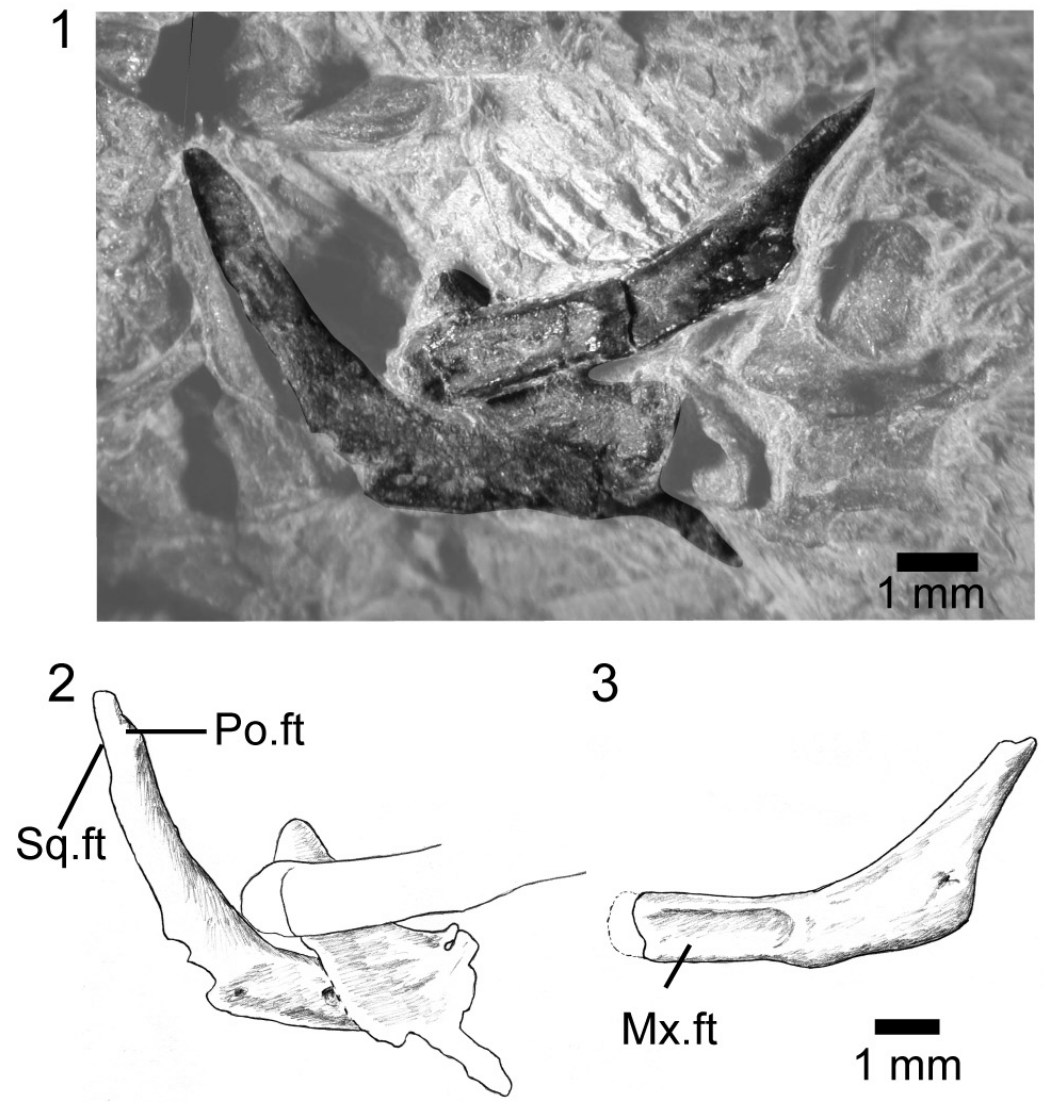

3
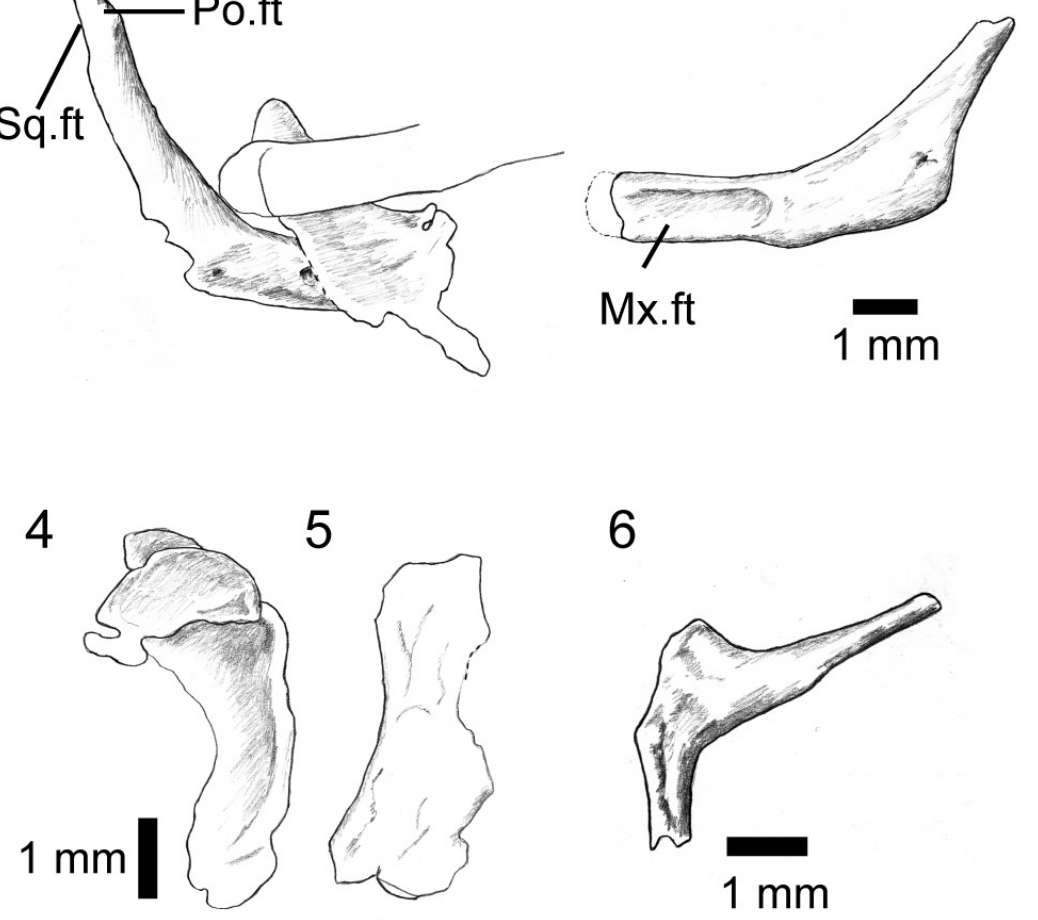

FIGURE 9. Asagaolacerta tricuspidens gen. et sp. nov., holotype, SBEI 1566, details of cranial bones. 1, left and right jugals; 2-3, explanatory drawings of right and left jugal respectively; 4-5, right quadrate in $\mathbf{4}$, lateral, and $\mathbf{5}$, anterior views; 6 , biradiate bone, possibly coronoid. For abbreviations, see Material and Methods.

$\sim 7.4 \mathrm{~mm}$ long, and the dentary was originally $8.5-$ $9.5 \mathrm{~mm}$ long. The posterior part of each dentary is obscured, and the tooth row may have extended further. The subdental ridge is deeper anteriorly than posteriorly, and there is little development of a subdental gutter. The anterior tip (left bone) is narrow, with a smooth internal surface and no trace of facets, pits, or grooves in the symphysial region. On the right, the splenial is in association, filling the posterior part of the Meckelian fossa but not extending to the symphysis (Figure 8.3). The fossa remains mainly medial, rather than becoming ventral anteriorly, but does appear to be restricted in height. Parts of the post-dentary series are in association but are poorly exposed and difficult to prepare further due to the superimposition of other elements. A bifurcate bone overlies the posterior part of the right dentary, in roughly the position for a coronoid although this identification remains ten- 
1
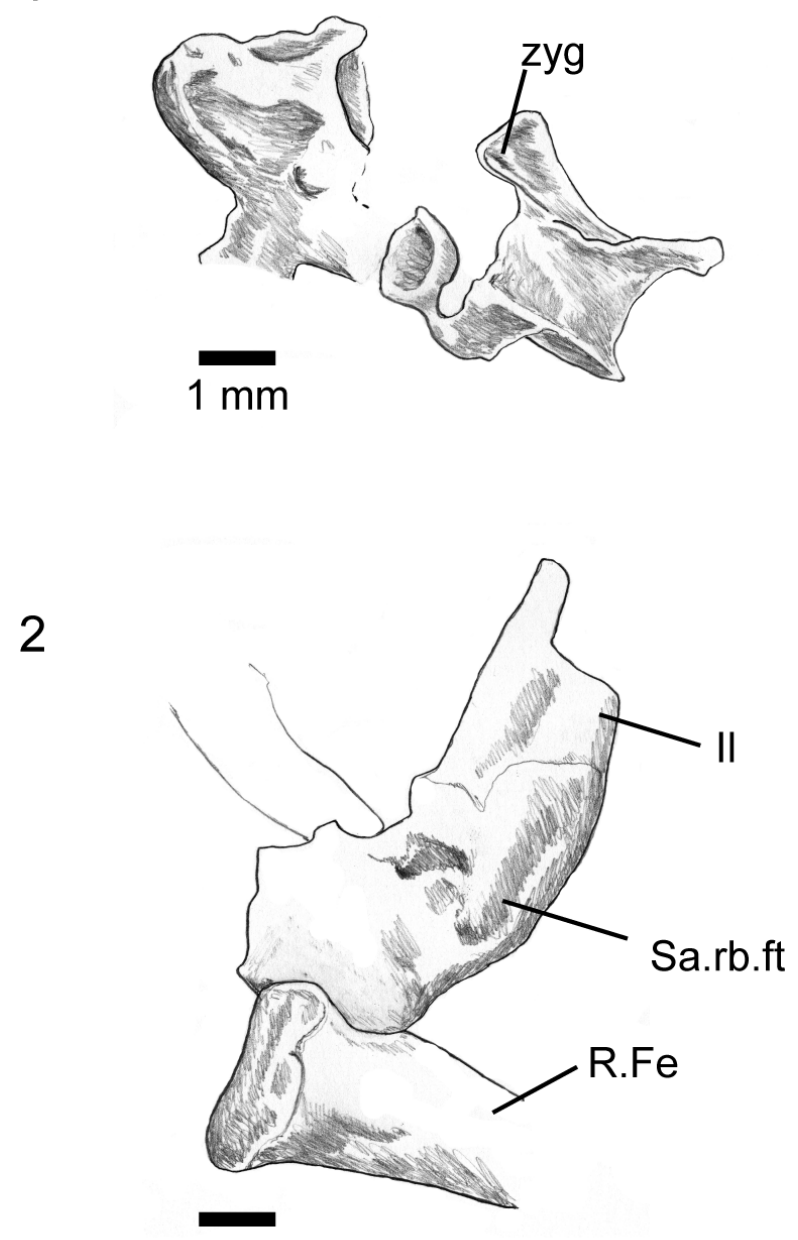

$1 \mathrm{~mm}$

FIGURE 10. Asagaolacerta tricuspidens gen. et sp. nov., holotype, SBEI 1566, postcranial elements. 1, presacral vertebrae; 2, left ilium and distal head of right femur. For abbreviations, see Material and Methods.

tative. Other robust bone fragments further posteriorly may be parts of the postdentary series.

The dentition is well exposed on the right dentary (Figure 8.3-4). The teeth are pleurodont and parallel-sided. The more anterior teeth are narrower and seem to have unicuspid crowns. The six exposed posterior teeth are larger and have a distinctive morphology. They are cylindrical with the crown of similar width to the tooth shaft. The crown is facetted with a strong sharp triangular central cusp and smaller lateral flanking cusps in a clearly tricuspid arrangement (Figure 8.4). Replacement pits are present in the base of several teeth showing replacement was active, lingual, and vertical.

Several vertebrae are scattered across the block (Figure 10.1). They are procoelous with slightly ovoid cotyles (long axis transverse), have low neural spines, and show a weak zygosphenezygantral system that resembles the condition in some modern lacertids, where the anterior articular surface is V-shaped in anterior view, with the zygapophysial and zygosphenoidal facets facing one another at an angle.

There is no trace of the forelimbs or pectoral girdle, but the central part of the block is a mass of overlapping elements that defies further preparation (or micro-CT visualisation) and it is possible that parts of the forelimb skeleton lie within this bone mass. The hind limbs are represented by part of the left pelvis, both femora, and some phalanges (some of which could also be from the manus). The left ilium is exposed in medial view (Figure 10.2), with the iliac blade broken across and superimposed on the underlying limb bones. It is difficult to reconstruct iliac shape with any accuracy but as preserved the blade has a shape similar to the iliac blade of unspecialised tetrapodal lizards. There is no evidence of a strong anterior tubercle. Depressions on the medial surface suggest the sacroiliac joint was close to the ilio-femoral one, rather than displaced distally as in some reduced limbed taxa. Adjacent to the ilium is a broader plate-like bone (not figured) which may be part of the ischium. Deep to these bones, and overlain by other fragmentary (and mostly unidentifiable) elements, there is an almost complete left femur (Figure 7), $11.3 \mathrm{~mm}$ as preserved but probably $11.5-12 \mathrm{~mm}$ in life as the proximal end is damaged and the distal condyle slightly distorted. The internal trochanter is present deep to the proximal femoral head. Only the distal part of the right femur is visible, but a micro-CT scan shows that the remainder of the bone lies deeper in the rock. By comparison with modern lizards, and taking into account the size of vertebrae and pelvic bones, these femora are similar in size and shape to the femora of living limbed lizards.

Additional specimens that may pertain to Asagaolacerta tricuspidens. SBEI 190 (Li1) and SBEI 193 (Li4) are blocks bearing postcranial remains of similar size and proportions to those on the holotype of Asagaolacerta tricuspidens.

SBEI 190 (Li1) (Figure 11.1-2) is a partial postcranial association bearing sacral vertebrae, posterior dorsal vertebrae, the left pelvis, and a left femur (12 mm long), tibia ( $7 \mathrm{~mm}$ ), and fibula on one block and more anterior dorsal vertebrae and ribs on a second block (not figured). The dorsal vertebrae are procoelous with rounded condyles, short square neural spines, weak zygosphenes, and 

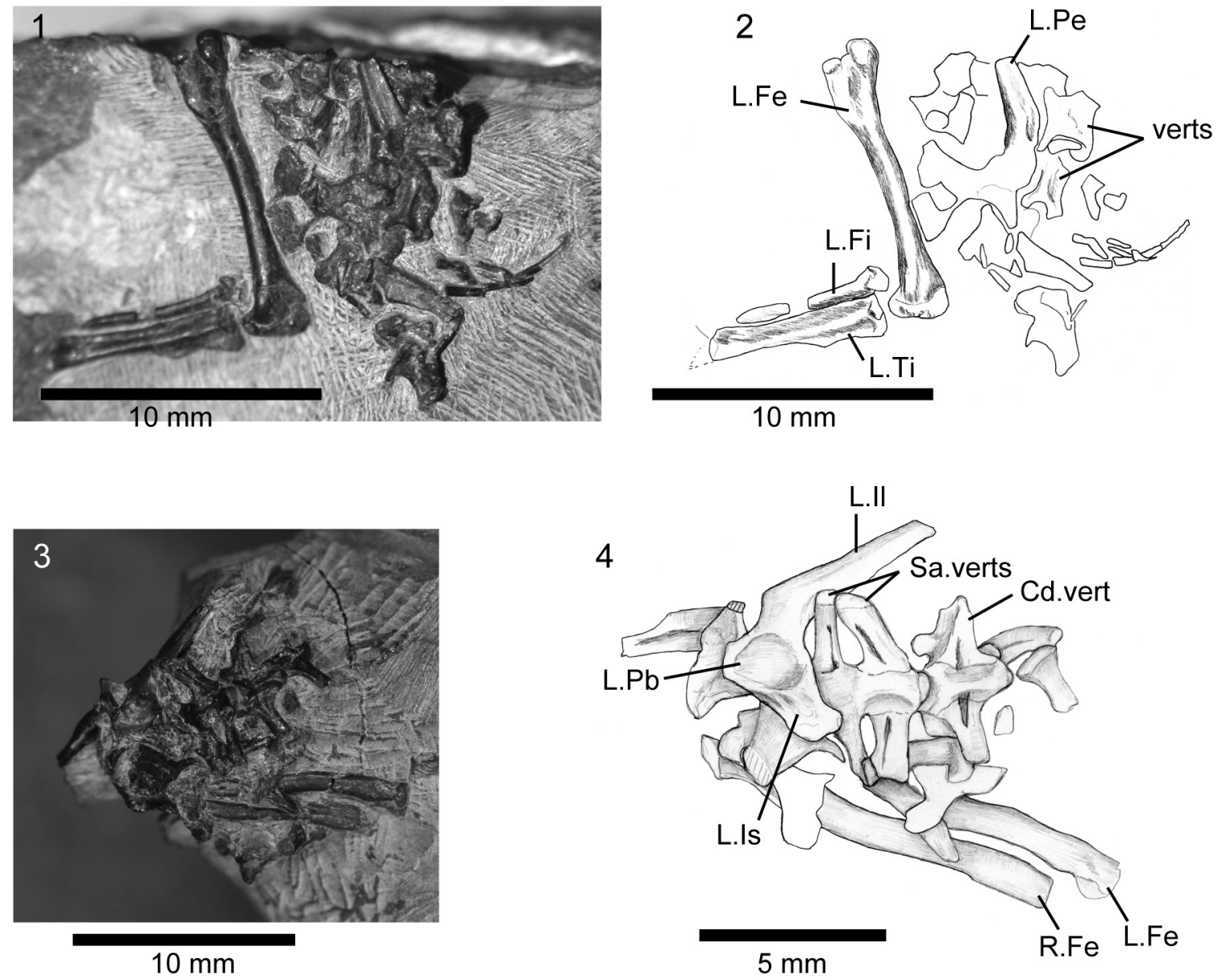

FIGURE 11. Associated postcranial specimens that may be referable to Asagaolacerta gen. nov. 1-2, SBEI 190; 3-4, SBEI 193. For abbreviations, see Material and Methods.

large oblique rib synapophyses. The sacrum is damaged. The pelvis is preserved in medial view and its components are co-ossified. The ilium is of similar shape to the ilium on the holotype of Asagaolacerta tricuspidens; the sacral rib facet is positioned just above the level of the acetabulum. The pubis is only partially preserved, but was clearly tapering rather than broad, and the ischium was flask-shaped. The femur is robust and has a thick circular shaft that has only a slight sigmoid curvature. The proximal and distal ends are fully ossified, with a rounded proximal femoral head, a well-developed tuber-like greater trochanter, and a distinct intertrochanteric fossa. The bone is relatively stouter than the femur of the holotype of Asagaolacerta tricuspidens (overall length/distal width $\sim 4.7$ compared to 6.2 in Asagaolacerta tricuspidens), although only slightly longer. The tibia is shorter than the femur $(\sim 58 \%)$ but again robust with a wider proximal end and a flange-like cnemial crest that is separated from the proximal end. The fibula was probably slight longer than the tibia but its distal end is broken. There are no associated osteoderms.

SBEI 193 (Li4) (Figure 11.3-4) is a second partial postcranial association, preserved in ventral view. The sacral vertebrae are fused and the conjoined distal ends of the sacral ribs enclose a foramen sacrale on each side. Rather unusually, the first sacral, though incomplete, appears to be less robust than the second. Behind them, the first caudal has a slight keel and robust transverse processes, each of which bears a deep linear groove proximally. The left pelvis is complete with the components conjoined. The right ilium is preserved in medial view. Its elongate blade lies at roughly $45^{\circ}$ degrees to the long axis of the acetabular region, with the sacral rib facet lying just above the level of the acetabulum. There is a slight anterodorsal expansion rather than a tubercle. Both femora ( $8.7 \mathrm{~mm}$ ) are preserved to one side of the block, although they are partially covered by disarticu- 
lated dorsal vertebrae. They are smaller than femora on the holotype of Asagaolacerta tricuspidens but they are otherwise similar in proportions (overall length/distal width $\sim 6.0$ in both SBEI 193 and SBEI 1566). Again, there are no associated osteoderms.

On the basis of the femoral and, to a lesser degree, iliac shape, one or both specimens may be attributable to Asagaolacerta tricuspidens but without more complete material they cannot be referred with confidence and characters from these specimens were not included in the diagnosis or phylogenetic analyses.

Affinities. Among extant lizards, tricuspid teeth are found mainly in iguanians, lacertids, and teiioids, although they may also occur in other groups. In the Mesozoic, tricuspidy is rarer (Nydam, 2002), but again occurs most commonly in taxa referred to Iguania or Borioteiioidea (sensu Nydam et al., 2007, =Polyglyphanodontia of Gauthier et al., 2012 and Longrich et al., 2012). One exception is the Late Cretaceous Mongolian Parmeosaurus scutatus (Gao and Norell, 2000), which our analysis grouped with scincoids. Of described Jurassic and Early Cretaceous lizard taxa, only Ptilotodon wilsoni from the Aptian-Albian Antlers Formation of Texas (Nydam and Cifelli, 2002b) approaches tricuspidy in having small anterior and posterior expansions that form shoulders on either side of a much larger central cusp. The teeth of Asagaolacerta tricuspidens differ in having distinct cuspules that are almost the same height as the central cusp. In the Late Cretaceous, tricuspidy became more common. It has been recorded in several Campanian-Maastrichtian genera from North America (Nydam, 2002; Longrich et al., 2012) that were once considered teiioid but have more recently (Nydam et al., 2007; Longrich et al., 2012) been classified as borioteiioid - notably Chamops segnis and Leptochamops denticulatus (Estes, 1964), Meniscognathus altmani (Nydam and Voci, 2007), Socognathus brachyodon (Gao and Fox, 1996; Longrich et al., 2012), Tripennaculus eatoni (Nydam and Voci, 2007), and Obamadon gracilis (Longrich et al., 2012), The first four of these have been grouped (with others) into the family Chamopsiidae (e.g., Nydam et al., 2010; Longrich et al., 2012), but they did not always emerge as a monophyletic unit in our analyses (Figure 12). Tricuspidy is also found in a range of borioteiioid taxa from Late Cretaceous deposits in Mongolia (Alifanov, 2000b), including Altanteius facilis, Cyclurasia multidentata, Mongolochamops reshetovi, Piramicephalosaurus cherminicus, and
Tchingisaurus multivagus. A borioteiioid attribution for Asagaolacerta would be consistent with the heterodonty and tricuspidy (e.g., Nydam and Cifelli, 2002a, 2002b), the paired unsculptured frontals, and the long postorbital ramus of the jugal. However, Asagaolacerta tricuspidens differs from many more derived borioteiioids in lacking a hypertrophied splenial and a heavy deposition of cementum around the tooth bases, characters that have been cited as diagnostic of both teiioids and borioteiioids (e.g., Denton and O'Neill, 1995; Gao and Fox, 1996; Nydam et al., 2007).

As for Kuroyuriella mikikoi, we coded Asagaolacerta tricuspidens into the matrix of Gauthier et al. (2012) and Longrich et al. (2012) (94/622 characters, $85 \%$ missing data). In all analyses, weighted and unweighted, constrained or unconstrained, ordered or unordered, Asagoalacerta was consistently placed on the stem of Borioteiioidea (Figure 12), although the position of the clade within the squamate tree varied with different protocols (e.g., Figure 5), as did the resolution and positions of in-group taxa (Figure 12). Although the strict consensus of the exhaustive analysis (unconstrained, unordered, equally weighted) placed Asagaolacerta in an unresolved position in relation to the fragmentary North American taxa (Figure 12.1), it is important to note that Asagaolacerta did not group with any one of these taxa in the more resolved individual trees from analyses using different protocols (e.g., Figures 12.2-12.4), nor when the borioteiioid taxa were run on their own (Figure 12.5).

$$
\begin{aligned}
& \text { SQUAMATA Oppel, } 1811 \\
& \text { Family indet. } \\
& \text { Genus HAKUSEPS gen. nov. }
\end{aligned}
$$

zoobank.org/6AD065FC-1D2E-488D-ABBB-5C27E306057D

Type species. Hakuseps imberis

Etymology. From Hakusan, white mountain, the name of the city of which Shiramine village forms a part and of the regional volcanic peak, and seps (L), variably used for lizard.

Diagnosis. As for type and only species

\section{Hakuseps imberis sp. nov.}

Figure 13

zoobank.org/11AC5FFE-4BA8-4D27-B149-A326E5AF2921

Etymology. From imber, imberis (L) meaning a shower, in reference to the shape of the dentary which resembles that of an inverted shower-head.

Holotype. SBEI 2086. An almost complete left dentary (Figure 13). 
1

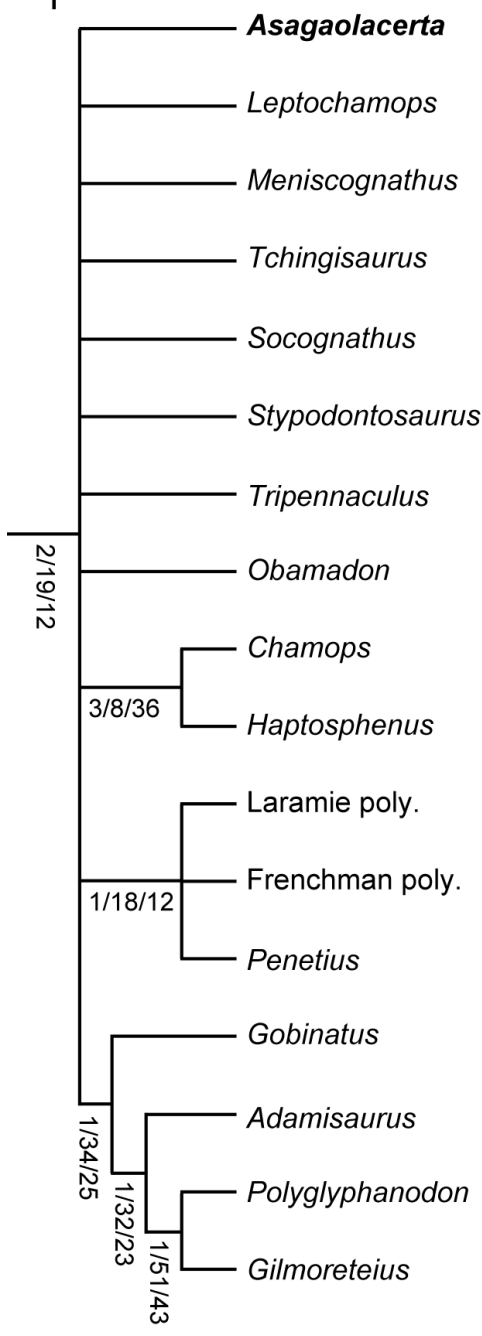

2

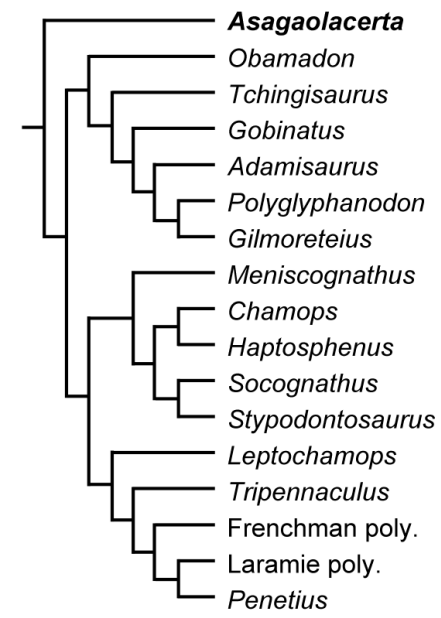

3

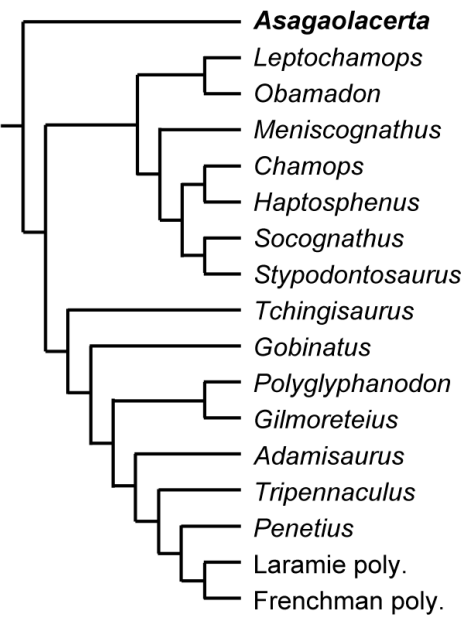

4

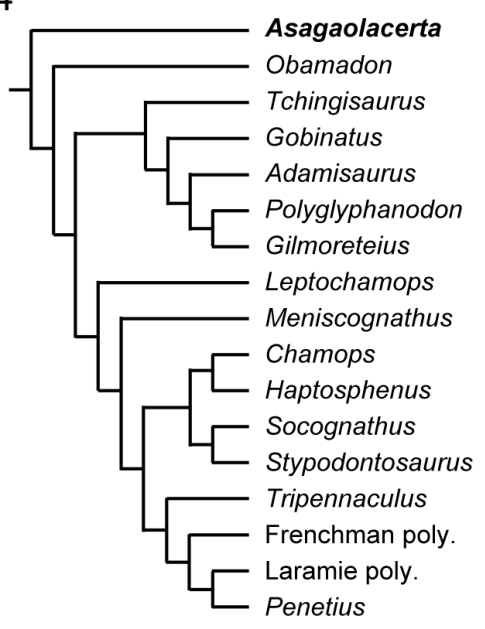

5

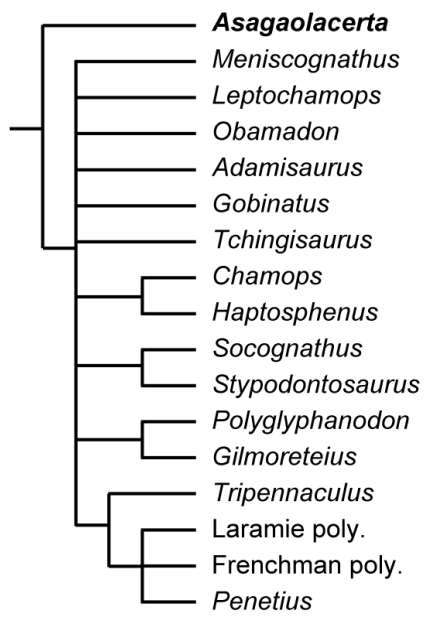

FIGURE 12. The phylogenetic position of Asagaolacerta tricuspidens gen. et sp. nov. tested using different analytical protocols within TNT. 1, detail of Strict Consensus of 1000 trees using the protocol that yielded the tree in Figure 5.1, node support values Bremer/Jacknife/Symmetric sampling; 2, one of three trees resulting from an analysis using with the molecular backbone constraint tree, but no character ordering or weighting; $\mathbf{3}$, one of 58 trees from an analysis run as in (2), but with character ordering as per Gauthier et al. (2012) and Longrich et al. (2012), and Implied Weighting $(k=7) ; 4$, one of 34 trees from an analysis run as in (3), but without the molecular backbone constraint; $\mathbf{5}, 70 \%$ MRT of 19 trees resulting from an analysis (characters ordered but equally weighted, no constraints) run using only the boreoteiioid taxa, with Gekko gecko as the outgroup taxon. The 70\%MRT is presented rather than the unresolved Strict Consensus to show that Asagaolacerta tricuspidens is usually (88\% of trees) placed in the basal position (see text for further discussion). Abbreviation: poly, polyglyphanodont (as used in Longrich et al., 2012).

Type locality and horizon. The Kaseki-Kabe, Shiramine, Hakusan city, Ishikawa Prefecture, Japan (Figure 1)

Referred material. None

Differential diagnosis. Small reptile (preserved dentary length $9.75 \mathrm{~mm}$ ) that differs from all known squamates, living and extinct, in having dentary with alveolar margin ending abruptly roughly halfway along the bone and leaving thick, strongly curved, edentulous border between posteriormost tooth and coronoid facet; somewhat resembles Early Cretaceous Pachygenys spp. from China (Gao and Cheng, 1999) and Japan (Ikeda et al., 2015) in edentulous margin and in short dentary tooth row (10 tooth positions versus 8 in Pachygenys), but differs in having heterodont dentition with unicuspid anterior teeth and bicuspid posterior teeth (versus homodont series of bluntcrowned teeth in Pachygenys), dentary dorsal and ventral margins fused without suture to enclose 
1

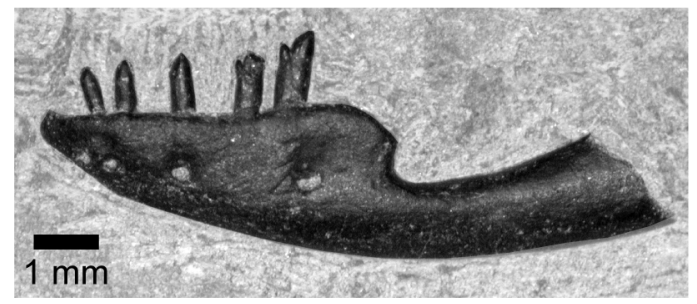

3

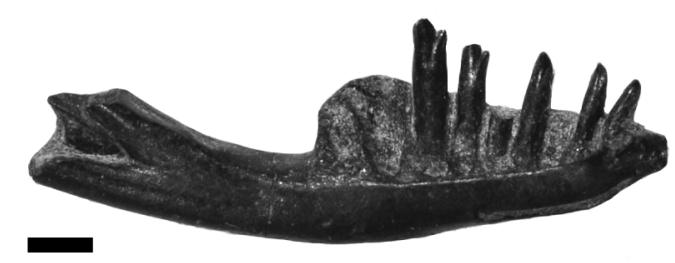

$1 \mathrm{~mm}$

5

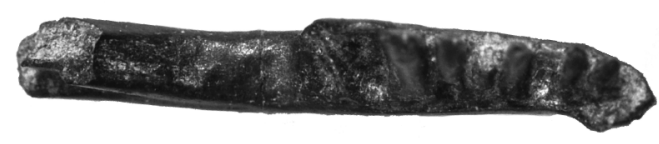

$1 \mathrm{~mm}$
2

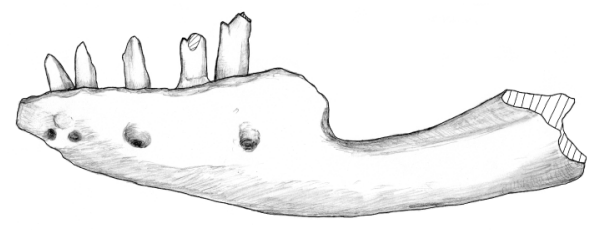

4

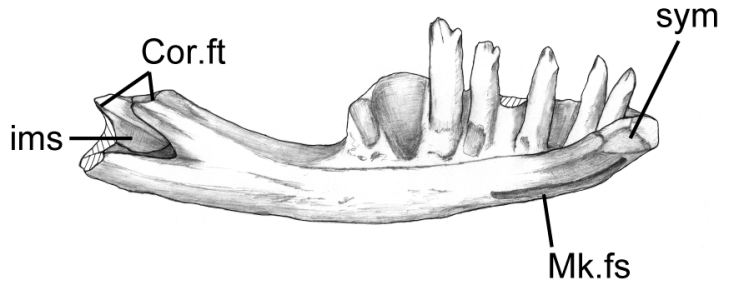

6

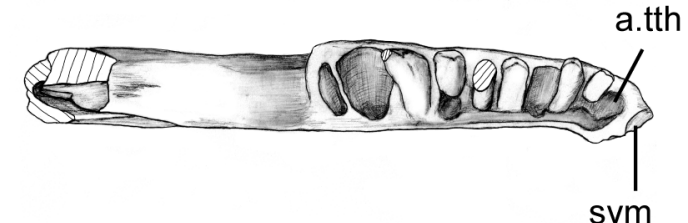

7

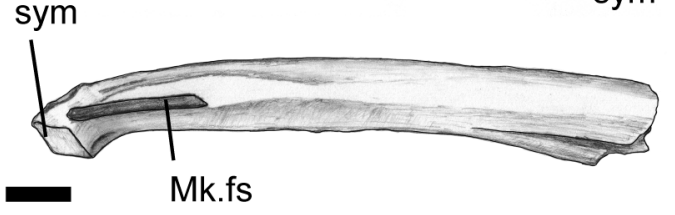

$1 \mathrm{~mm}$

FIGURE 13. Hakuseps imberis gen. et sp. nov., holotype left dentary, SBEI 2086. 1-2, labial view; 3-4, lingual view; 5-6, occlusal view; and 7, ventral view. For abbreviations, see Material and Methods.

Meckelian fossa (versus deep fossa filled by separate splenial in Pachygenys), and posterior edentulous region completely separated from tooth row (contiguous with it in Pachygenys).

Material. SBEI 2086 (Li275) is a left dentary, originally preserved in labial view but prepared from the matrix to reveal its lingual aspect.

Description. The bone is divided into two parts of roughly equal length (Figure 13). The alveolar (dental) margin is limited to the anterior half of the bone. It has a total of ten tooth positions, five of which bear complete teeth. The implantation is pleurodont, but the teeth protrude well above the labial wall of the jaw. The anteriormost tooth position lies immediately adjacent to the symphysis and is visible only in occlusal view (Figure 13.7). The teeth are heterodont, unicuspid anteriorly, with a concave lingual surface flanked by weak mesial and distal crests, and distinctly bicuspid posteriorly, with a small divergent mesial cusp and a broader distal cusp. The tooth in the fifth position (third complete) is intermediate in crown morphology, essentially resembling the anterior teeth but bearing a slight protrusion on the mesial edge in the position occupied by the cuspule in more posterior teeth. The teeth also increase in basal diameter along the row, with the missing penultimate tooth represented by a gap that is more than twice the diameter of anterior teeth. The last tooth position is much smaller. Tooth replacement was lingual, replacement pits being present at the bases of the teeth in positions five and seven. The anterior tip of the bone narrows dorsoventrally, but maintains its width labiolingually to form a distinct symphysial surface. This surface is supported by a deep subdental ridge below which the Meckelian fossa 
opens for the short distance anteroventrally (Figure 13.3-4). However, at the level of the sixth tooth position, the dorsal and ventral margins of the dentary fuse to fully enclose the Meckelian canal.

Half way along the bone, as preserved, the labial wall supporting the alveolar margin ends abruptly, creating a distinct step in the dorsal edge of the bone. This morphology is not the result of post-mortem damage, the bone surfaces are intact and smooth (unfacetted). The posterior half of the dentary is composed only of its cylindrical ventral portion, enclosing the Meckelian canal, the inferior alveolar nerve, and blood vessels. As a result, the dentary as a whole rather resembles a showerhead or a small hand brush. The "handle" curves posterodorsally but the posterior end of the bone is missing. The posterolingual wall is deeply incised. There is no trace of a splenial facet and this element was either absent or fully fused into the dentary. Immediately above the posteromedial incision, the rising dorsal edge of the bone bears a very shallow depression, flanked dorsolabially by a slight ridge. This depression may represent a weak coronoid facet, but this interpretation is tentative. Posteroventral to it, a vertical sheet of bone extends between the incised lingual wall of the dentary and the rounded labial one. This sheet appears to have a free ventral margin (although it cannot be fully prepared out from the matrix filling the Meckelian fossa as the walls are thin) and may represent an intramandibular septum, separating the Meckelian canal from the inferior alveolar canal laterally. The dorsomedial edge of the septum bears a facet, again possibly for part of the coronoid. The remaining postdentary bones (surangular, angular, prearticular), separately or conjoined, would have slotted into the back of the dentary, but they must have done so at a distinct angle to the horizontal given the strong curvature of the ventral dentary margin.

Four small nutrient foramina pierce the labial surface.

Affinities. This unusual dentary is attributed to the Squamata on the basis of tooth implantation and the general morphology of the anterior part of the jaw. However, it is unlike the dentary of any known lizard, with the partial exception of the roughly contemporaneous species Pachygenys thlastesa (Gao and Cheng, 1999) (Figure14.1-2). Pachygenys was based on two mandibles from Early Cretaceous deposits in Shandong Province, China. Recently, however, closely similar jaws were recovered from the Sasayama Group of Hyogo Prefecture, Japan (Ikeda et al., 2015), dated as early
Albian (112 Ma, Kusuhashi et al., 2013) and named Pachygenys adachii. As in Hakuseps imberis, the dentary of Pachygenys thlastesa is curved and has small number of teeth (eight) concentrated at the anterior end of the dentary. However, although the posterior region of the dentary of Pachygenys is also edentulous, the labial wall remains intact rather than being stepped (Figure 14.1). Furthermore, below the tooth row, the lingually open Meckelian fossa is filled by a large free posteriorly deep splenial (Figure 14.2). This splenial is pierced just posterior to the level of the last tooth by the anterior inferior alveolar foramen, behind which is the anterior mylohyoid foramen. Pachygenys also has blunt-crowned homodont teeth, unlike the heterodont dentition of Hakuseps with its strongly bicuspid posterior teeth. The two genera could be related, but given that both are represented only by partial mandibles, their phylogenetic position within Squamata is difficult to ascertain. Pachygenys has been referred to "scincomorphs" (Gao and Cheng, 1999) or lacertoids (Ikeda et al., 2015). Hakuseps imberis was not included in the phylogenetic analyses as it preserves too few codable characters.

Among extant lizards, some xantusiids have a short edentulous region behind the tooth row. However, this morphology more closely resembles the condition in Pachygenys thlastesa than Hakuseps imberis, and the tooth row is longer and the edentulous region shorter. Xantusiids also show the complete dentary enclosure of the Meckelian fossa seen in Hakuseps, but this feature occurs convergently in gekkotans and in some scincids, gymnophthalmids, and occasional members of other clades, and seems to be a way of strengthening the jaw against bending. An intramandibular septum that extends to the posterior end of the dentary (and has a free margin) has been considered an anguimorph synapomorphy associated with a reduced overlap of dentary and postdentary bones (e.g., Estes et al., 1988), although it can occur in other taxa (e.g., some chameleons, Estes et al., 1988). However, mesio-distally bicuspid teeth with lingual tooth replacement are more usually associated with lacertoids (notably teiids, gymnophthalmids, and lacertids), although bicuspidy can occur in other groups. In fossil lizards, it is recorded in the Early Cretaceous Meyasaurus spp. (=llerdaesaurus, Hoffstetter, 1966) from Spain (e.g., Richter, 1994; Evans and Barbadillo, 1997) and Britain (Sweetman, 2009; Sweetman and Evans, 2011). Like Hakuseps, the anterior teeth in all Meyasaurus species are unicuspid and the posterior teeth bicuspid, but there 
1

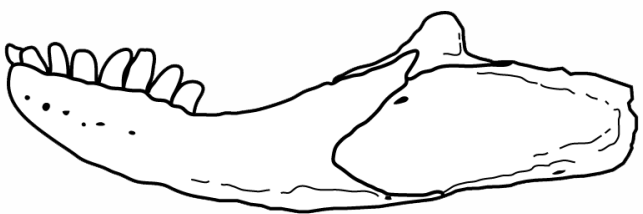

3

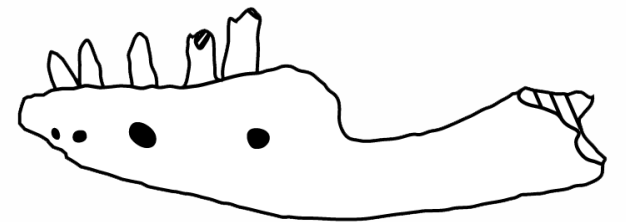

2

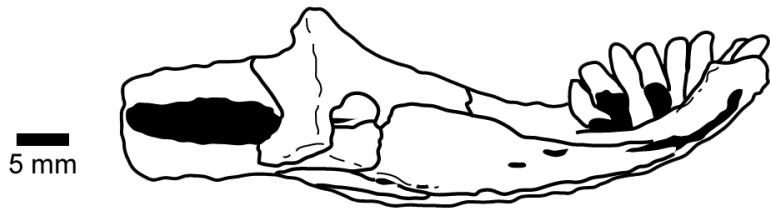

4

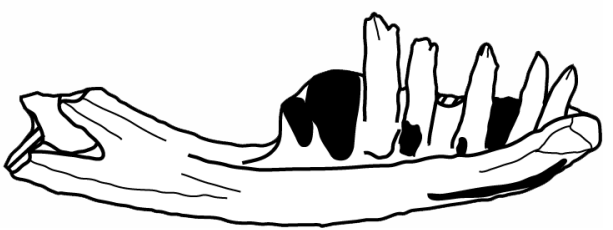

FIGURE 14. Comparison of Pachygenys thlastesa (Gao and Cheng, 1999) and Hakuseps imberis gen. et sp. nov. Labial and lingual views respectively of 1-2, Pachygenys thlastesa (redrawn from Gao and Cheng, 1999), 3-4, Hakuseps imberis gen. et sp. nov.

the resemblance ends. Meyasaurus has variously been placed with teiids (Evans and Barbadillo, 1997), anguimorphs (Richter, 1994; Conrad, 2008; Bolet and Evans, 2011), cordyliforms (Müller et al., 2011), or in an unresolved position amongst crown squamates (Bolet and Evans, 2010). Bicuspidy has recently been reported in a second Spanish taxon, Pedrerasaurus latifrontalis (Bolet and Evans, 2010), in jaws (unnamed) that occur with Meyasaurus sp. in the Barremian Wessex Formation (UK, Sweetman and Evans, 2011), and in another Tetori taxon (see below) with "normal" jaws. In all of these taxa, a small anterior cusp precedes a large posterior cusp, but the anterior cusp is divergent only in Hakuseps imberis, and none of the other taxa shares the atypical jaw morphology.

A jaw morphology somewhat similar to that of Hakuseps imberis, with the posterior half dentary being much shallower than the anterior half, and having a strong upward curvature, is found in some scolecophidian snakes (e.g., Leptotyphlops dulcis, Kley, 2014). However, without further material, this strange squamate remains an enigma. The sharp pointed teeth suggest a diet of small invertebrates, but their unusual arrangement (and the overall shape of the jaw) implies a specialised feeding strategy. In the absence of the maxilla and premaxilla, however, it is difficult to understand how the jaws might have been used.

\section{SQUAMATA Oppel, 1811 \\ Family indet. \\ Morphotype A}

Figure 15
Material. Within the Shiramine lizard collection there are several maxillae and dentaries with bicuspid teeth, notably SBEI 1501 (Li191) and 1525 (Li193), a right and left maxilla respectively (Figure 15.1-4); SBEI 197 (Li8) and 808 (Li92) (Figure 15.5-10), both left dentaries; and SBEI 1487 (Li190), a right dentary. In all, the accessory cusp is smaller and less divergent than the corresponding cusp of Hakuseps imberis.

Description. SBEI 1501 (Li191) and SBEI 1525 (Li 199) both represent the anterior maxilla. SBEI 1525 is a left maxilla, $4.7 \mathrm{~mm}$ long, with 10 tooth positions (Figure 15.1-2). The last four preserved teeth are bicuspid (from tooth position five or six). Although the dorsal margin of the premaxillary process is oblique, the anterior tip is recurved. SBEI 1501 (Figure15.3-4) is a right maxilla, $2.6 \mathrm{~mm}$ long, that preserves 12 tooth positions. The anterior teeth are damaged but the posterior ones (from tooth position 8) are bicuspid. The anterior narial margin of the bone is smoothly oblique, with no step or angulation between ventral and posterior components. In this respect it resembles the maxilla of Asagaolacerta tricuspidens, but is less than half of its size. It is possible that this maxilla originally bore a recurved tip like that of SBEI 1525 .

SBEI 808 (Li92) is a shallow left dentary, preserved in two pieces, both in labial view (Figure15.5-10). The reconstructed length is $\sim 7.9 \mathrm{~mm}$, with a posterior depth of $\sim 1.6 \mathrm{~mm}$. The bone tapers at the symphysis, and there are six large labial neurovascular foramina. Fourteen teeth are preserved with at least 10 empty tooth positions, more than twice the number in Hakuseps imberis. The 
1

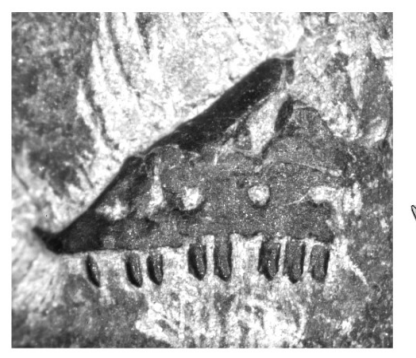

2

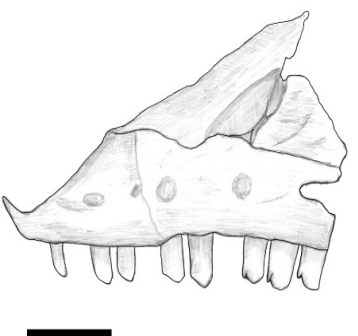

$1 \mathrm{~mm}$
3

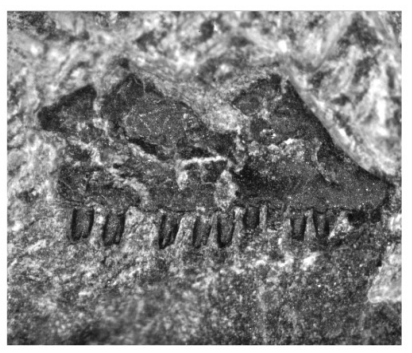

4

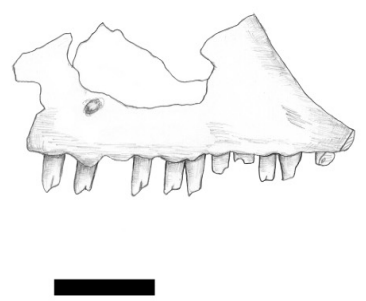

$1 \mathrm{~mm}$
5

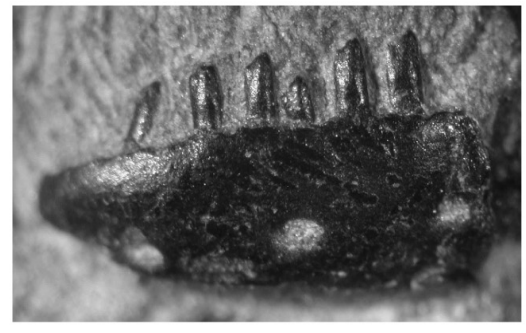

7

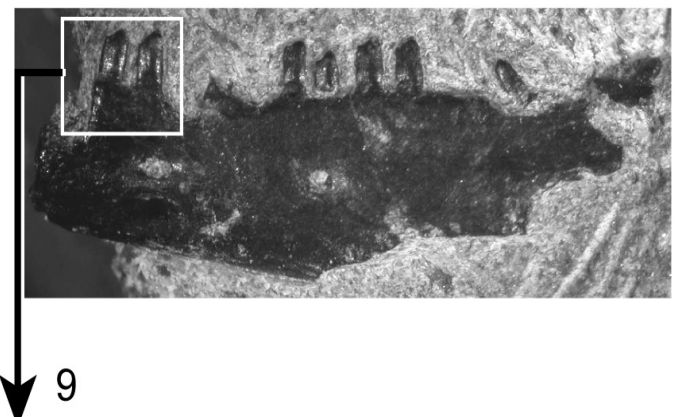

$1 \mathrm{~mm}$
6

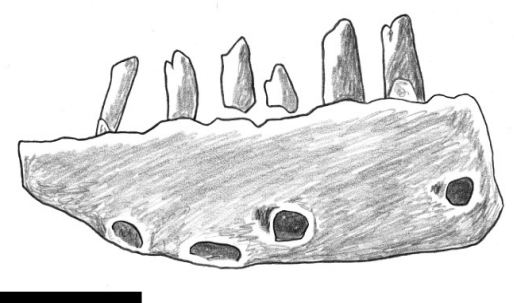

8

10
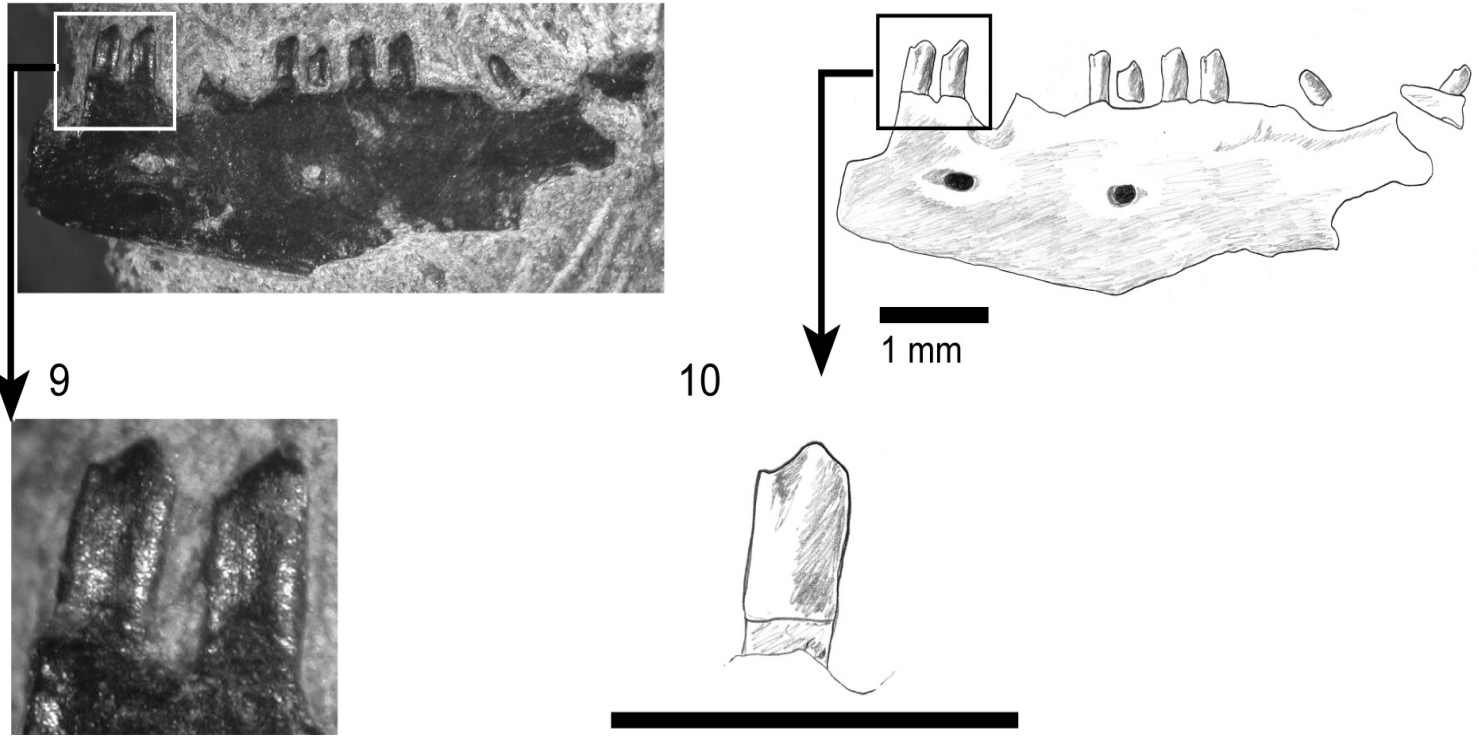

$1 \mathrm{~mm}$

FIGURE 15. Shiramine Morphotype A, bicuspid dentition. 1-2, left maxilla, SBEI 1525 in labial view; 3-4, right maxilla, SBEI 1501, in labial view; 5-10, left dentary, SBEI 808, in two parts, in labial view, with 5-6, symphysial region, 7$\mathbf{8}$, posterior dentary, and 9-10, detail of bicuspid teeth.

dorsal margin of the dentary is scalloped, with the edge expanding slightly at the base of each tooth. There is also some cementum around the tooth bases. Most of the tooth crowns are preserved and they are visibly bicuspid with a small anterior cusp and a large posterior one (Figure 15.9-10). The second preserved tooth, which is probably the fourth or fifth in position (allowing for at least two small symphysial tooth positions), is already bicuspid. The teeth are quite long and narrow in labial view (exposed height/width 1.9). SBEI 808 is supplemented by two smaller specimens, SBEI 197 
(Li8) and SBEl 1487 (Li190) (not illustrated), with similar teeth.

Affinities. Given that these bicuspid jaw remains are generally smaller than the jaws of Asagaolacerta tricuspidens, one possibility is that they represent juveniles of that taxon. Ontogenetic variation in cusp number is known to occur in some modern lizards (e.g., lacertids, Barahona and Green, 1997), and variation can also occur along the tooth row. However, although none of the bicuspid jaws is complete, SBEl 808 has at least 24 tooth positions, almost double the number found in Asagaolacerta tricuspidens, and none is tricuspid. This high tooth count also rules out relationships with Hakuseps imberis and suggests the second kind of bicuspid jaws may represent a distinct lizard taxon, intermediate in size between Kuroyuriella mikikoi and Asagaolacerta tricuspidens.

As noted above, mesio-distal bicuspidy is relatively rare in Mesozoic lizards. The dentition of this second bicuspid Japanese lizard differs from the condition in Meyasaurus in which the anterior dentary teeth are unicuspid and become bicuspid halfway along the tooth row. SBEI 808 shows bicuspidy in anterior dentary teeth (from at least tooth position four). The dentary of Pedrerasaurus latifrontalis is poorly known but, as in the Japanese lizard, it is relatively shallow and bicuspid teeth were present more anteriorly in the tooth row than in Meyasaurus spp. (Bolet and Evans, 2010). In the maxilla, both have unicuspid anterior teeth, with bicuspidy occurring at about tooth position 8-9 in Pedrerasaurus latifrontalis and at 5-6 in the Japanese lizard. However, without more complete specimens, it would be premature to attach a name to any of these bicuspid jaws as they cannot be diagnosed with assurance.

\section{SQUAMATA Oppel, 1811 \\ Family indet. \\ Morphotype B}

Figure 16

Material. SBEI 827 (Li100) is a small right mandible separated into its dentary and postdentary components (Figure 16). The dentary is $4.5 \mathrm{~mm}$ long as preserved but is missing the symphysial region and posterior margin (estimated original total length $\quad \sim 5.7 \mathrm{~mm}$ ). The postdentary complex is $4.8 \mathrm{~mm}$ long, giving an overall original jaw length of $\sim 10.5 \mathrm{~mm}$. The specimen is delicate and is held together by a preservative that obscures some of the detail but which cannot be removed without risk of damage.
Description. The dentary bears at least 15 small, closely-packed unicuspid pleurodont teeth (Figure 16.3-4). Allowing for the missing symphysial region, there may originally have been about 20 teeth. These teeth are slightly spatulate lingually but taper abruptly into small pointed tips (SEM not possible due to the fragility of the specimen and preservative covering). Where visible anteriorly, the subdental ridge is deep and there is a narrow gutter between the tooth bases and the edge of the ridge. The Meckelian fossa seems to be closed anteriorly by the dentary alone but behind this closure, a long splenial obscures the rest of the fossa. The splenial is slightly disarticulated and has been displaced anteromedially, probably by about four tooth positions. It is narrow anteriorly and deepens posteriorly, but a dorsal embayment at the posterior end appears to be real. By comparison with modern lizards, this embayment probably originally underlay the coronoid region. The dentary extends behind the tooth row, expanding dorsally into a large coronoid process that would have covered at least part of the lateral surface of the coronoid bone. Seen in lateral view (Figure 16.1-2), and allowing for preservational artefact, the dentary shows a marked anterior to posterior increase in height.

The postdentary bones appear, at first, to be co-ossified, with a deep anterior notch between dorsal and ventral processes (Figure 16.5-10). However, although the surangular and articular/ prearticular are fused, the narrow angular is separate and has disarticulated labially so that it forms the lower margin of the apparent notch. A thin fragment of bone anterior to this notch may be part of the posterior process of the dentary. The surangular is shallow and bears lateral facets for the dentary, and angular and medial facets for the coronoid. Along its lateral face is a low surangular crest marking the ventral limit of the superficial adductor muscle mass. Even allowing for some distortion, the postdentary bones at their anterior margin are much shallower than the posterior part of the dentary, and a large coronoid presumably filled part of the gap between them. The surangular has a tongue-like anterior extension but this flange is short and is unlikely to have penetrated the Meckelian fossa of the dentary to any significant degree. Medially, the surangular and articular/ prearticular enclose a small shallow posterior adductor fossa. The articular surface for the quadrate is small, broad, and almost vertical, suggesting that the quadrate was oriented at an oblique angle to the rest of the skull. There is no evidence 


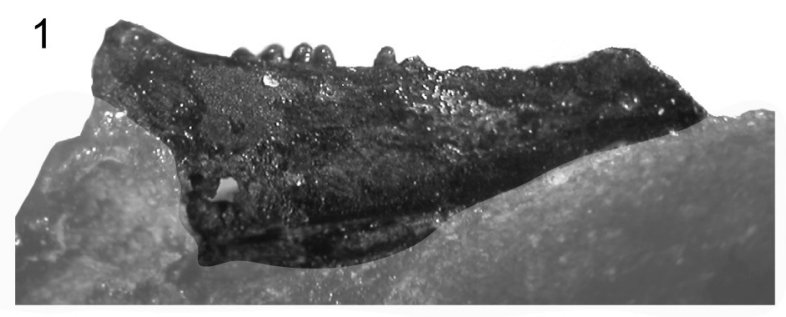

\section{2}
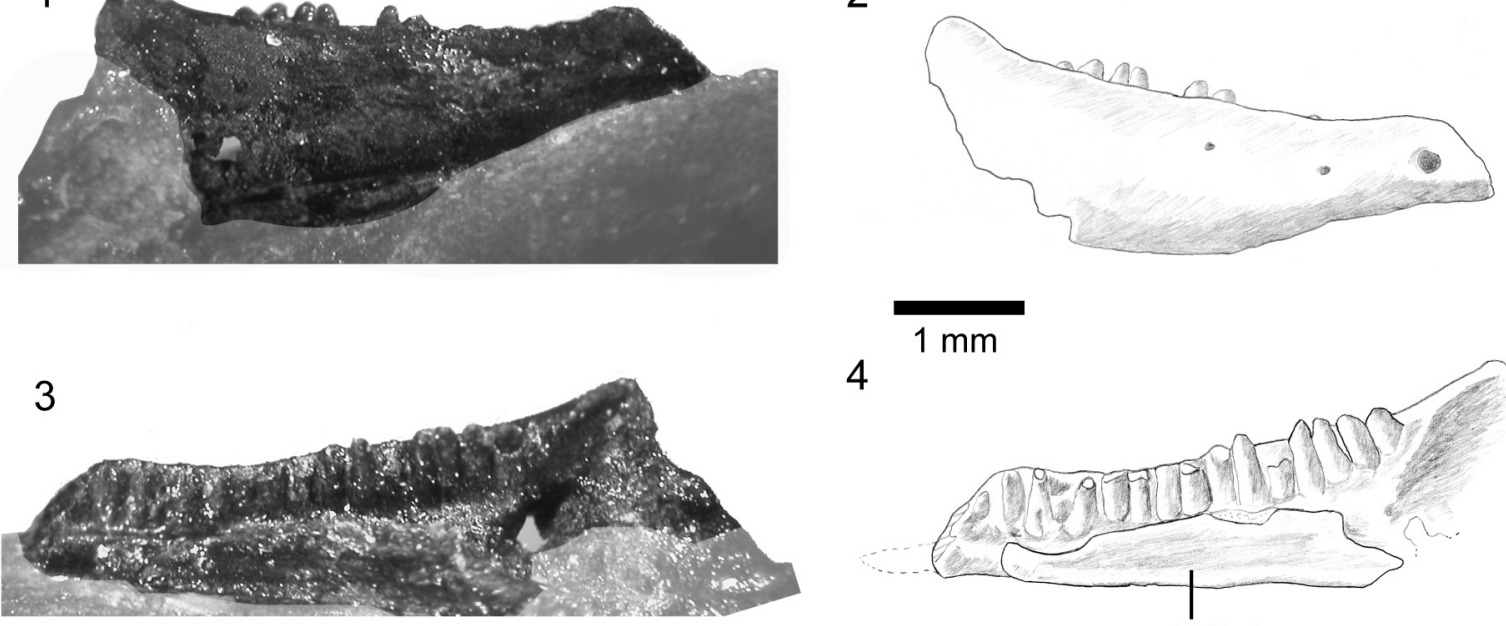

4

$1 \mathrm{~mm}$
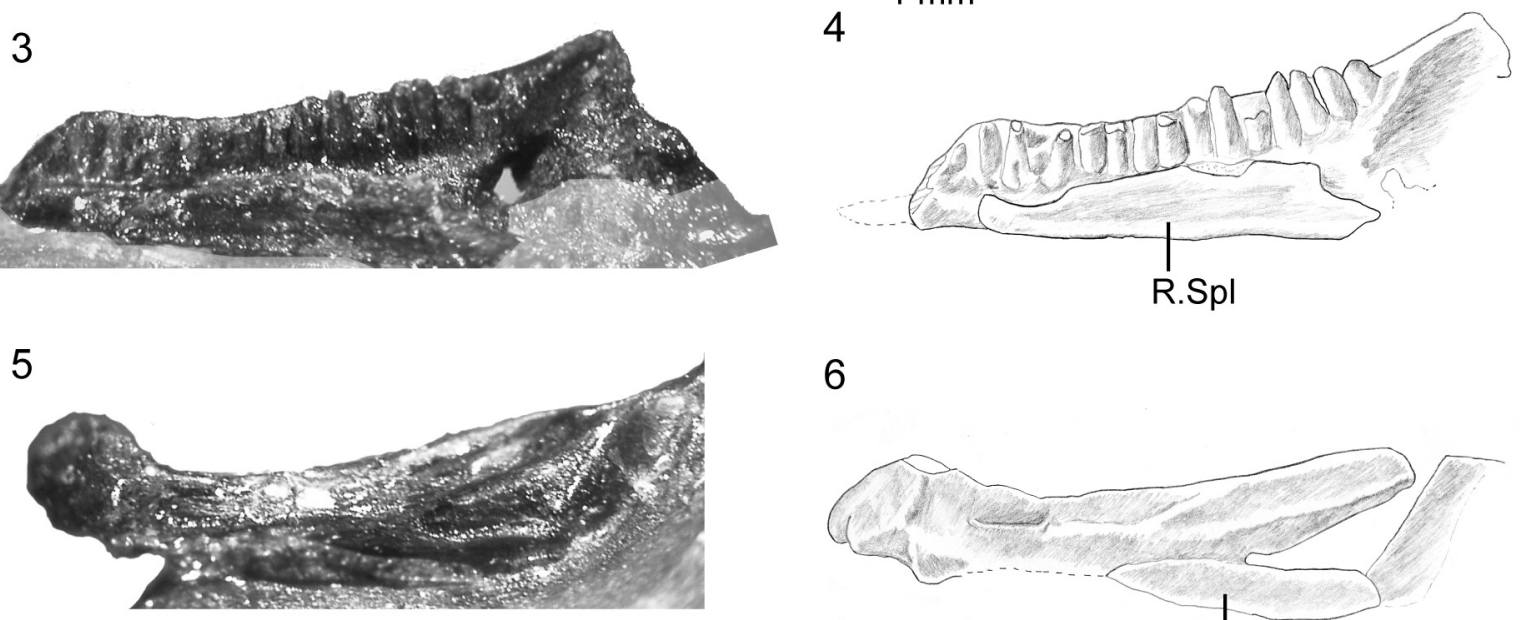

6
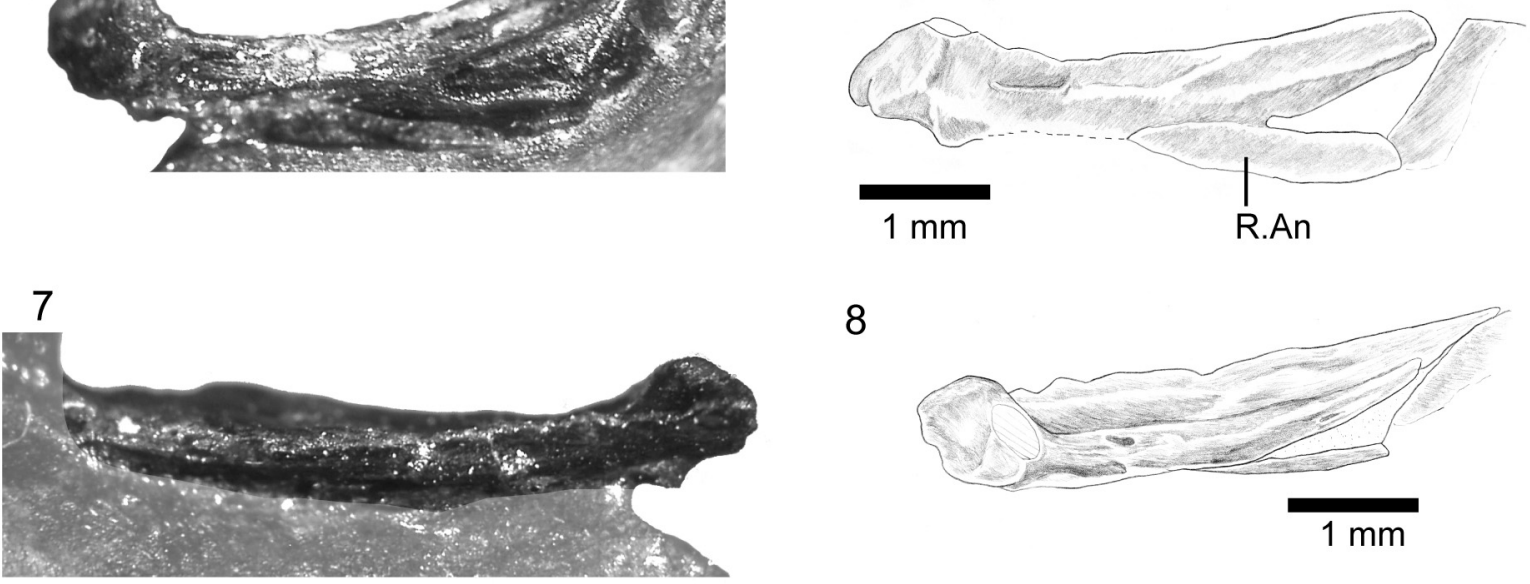

8

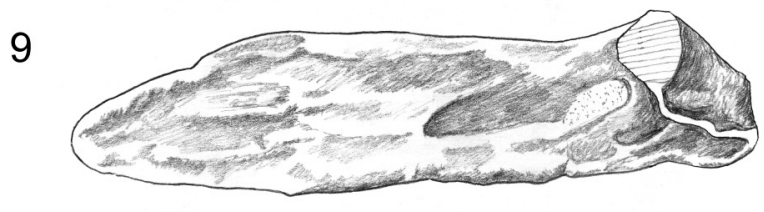

$1 \mathrm{~mm}$

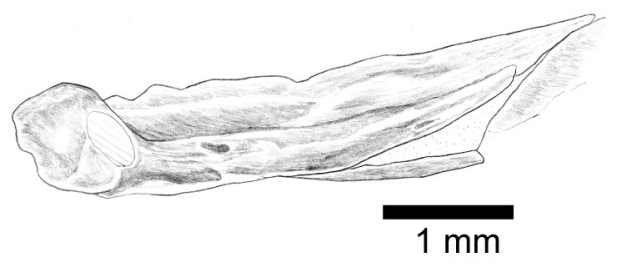

10

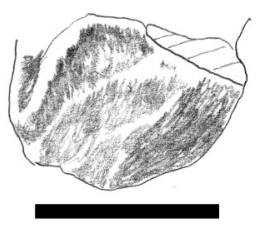

$1 \mathrm{~mm}$

FIGURE 16. Shiramine Morphotype B, right mandible SBEI 827. 1-2, dentary in labial view; 3-4, dentary and associated splenial in lingual view; 5-11, postdentary bones in 5-6 dorsomedial view; 7, ventral view; 8, dorsal view; 9, medial view; and 10, posterior view of articular surface. For abbreviations, see Material and Methods.

of a retroarticular process but, if thin, this process may have broken off without leaving an obvious edge.

Affinities. In tooth number and the presence of a coronoid process, SBEI 827 resembles the jaws of Kuroyuriella mikikoi, but the jaw shape is com- pletely different (anterior/posterior height difference), the coronoid process is larger and broader, the splenial is deeper, and the angular is shallower. The tightly packed pleurodont teeth, partial dentary closure of the Meckelian fossa, posterior extension of the dentary, co-ossification of the surangular and 
articular/prearticular, and small size of the adductor fossa are features shared with extant gekkotans, and this jaw was tentatively attributed to that group in a previous review (Evans and Manabe, 2000). However, gekkotans generally have larger numbers of teeth; do not have a large dentary coronoid process; lose or reduce the splenial; and lose a free angular in all except some eublepharids. Gekkotans are rare in the Mesozoic fossil record. The earliest recorded taxon is Hoburogekko suchanovi from Höovor (Aptian-Albian) in Mongolia (Alifanov 1989, 1990; Daza et al., 2012, 2014), but the associated dentary lacks postdentary bones and has a fully open Meckelian fossa. Another possible stemgekkotan (as yet unnamed) was described (Conrad and Norell, 2006) from Öösh, Mongolia (Berriasian to Albian, Andres and Norell, 2005; Berriasian to Barremian, Turner et al., 2007). Like the Tetori specimen, it has a large splenial covering a largely open Meckelian fossa and a small angular, but it lacks a dentary coronoid process and the surangular and articular/prearticular are not fused. The Late Cretaceous Gobekko (Borsuk-Białynicka, 1990; Daza et al., 2013) has a very poorly preserved jaw making comparison difficult.

Many characters of SBEI 827 (fusion or partial fusion of postdentary bones, partial closure of the Meckelian fossa by the dentary, posterior extension of the dentary, reduced angular) occur in individual members of other squamate clades including pleurodont iguanians, scincids, cordyliforms, xantusiids, gymnophthalmids, and xenosaurs (Evans, 2008). A subset of these clades share other features of SBEI 827, notably the welldeveloped dentary coronoid process (scincids, cordyliforms, and xantusiids), the small adductor fossa (scincids, xenosaurs, gerrhosaurid cordyliforms), and a sublingual gutter (xantusiids, cordyliforms), but in xantusiids the adductor fossa is large and the Meckelian fossa is usually closed by the dentary and a co-ossified splenial.

Myrmecodaptria microphagosa Gao and Norell, 2000 is an enigmatic Late Cretaceous Gobi lizard currently represented by a single skull. Gao and Norell (2000) referred it to Gekkota, but it lacks gekkotan characters and subsequent phylogenetic analyses have not supported this attribution (Conrad and Norell, 2006; Conrad, 2008; Gauthier et al., 2012; Daza et al., 2014). Conrad (2008) placed it on the stem of Autarchoglossa (scincomorphs + anguimorphs, sensu Estes et al., 1988), whereas Gauthier et al. (2012) sited it on the scincid stem, and our analyses recover it in the same position usually in a clade with Carusia (Figure 6). SBEI
827 resembles Myrmecodaptria (Figure 17.1-2), in having a jaw that deepens strongly from anterior to posterior, as well as a large dentary coronoid process, a large splenial, fusion of the postdentary bones, the near vertical orientation of the articular surface for the quadrate, and a posterior extension of the dentary. Some of these features are also present in Carusia intermedia (Borsuk-Białynicka, 1985), although the jaw shape is markedly different. The jaw of Myrmecodaptria microphagosa does have a retroarticular process, apparently absent in the Japanese jaw. Both fossils show some resemblance in jaw morphology (posterior deepening, large dentary coronoid process, nearvertical articular surface) to the rare living burrower, Dibamus spp.

Two other disarticulated elements in the Shiramine collection also resemble bones in Myrmecodaptria microphagosa and are of comparable size to SBEI 827. SBEI 2407 (LI304: Figure 17.4) is an almost complete left maxilla preserved in labial view (3.35 $\mathrm{mm}$ along the alveolar margin). It preserves only six sharp unicuspid teeth but has spaces for up to 18 others. The premaxillary process is oblique but, as preserved, the facial process extends anterodorsally creating an overhang that partially closes the narial opening. This arrangement could be a preservational artefact, but closely resembles the same region in Myrmecodaptria microphagosa (Gao and Norrell, 2000, Figure 17.1). In SBEI 2407, the posterior margin of the facial process inclines gradually to form a deep orbital process. Only at the end of the bone is there a sharp step. The maxilla probably formed most of the ventral orbital margin in this lizard with much of the jugal hidden in lateral view by the deep maxilla.

SBEI 1803 (Li253, Figure 17.5) is an almost complete median frontal $(\sim 2 \mathrm{~mm}$ across the preserved anterior margin, and $1.3 \mathrm{~mm}$ between the orbits). There is no trace of a midline suture and the facets for adjacent bones are well formed, suggesting maturity despite the very small size. The dorsal surface bears weak tuberculate sculpture. Small shelves on the anterior margins are probably the edges of the nasal facets. Prefrontal facets extend along the anterolateral margins of the bone for almost two-thirds of its preserved length, although it is not clear how much of the bone has been lost posteriorly. The bone is embedded in matrix and the small size limits preparation. However, exposure of the ventrolateral edges shows that the subolfactory crests (cristae cranii) extended medially as well as ventrally, although it is not clear how far. Asagaolacerta tricuspidens, 
1

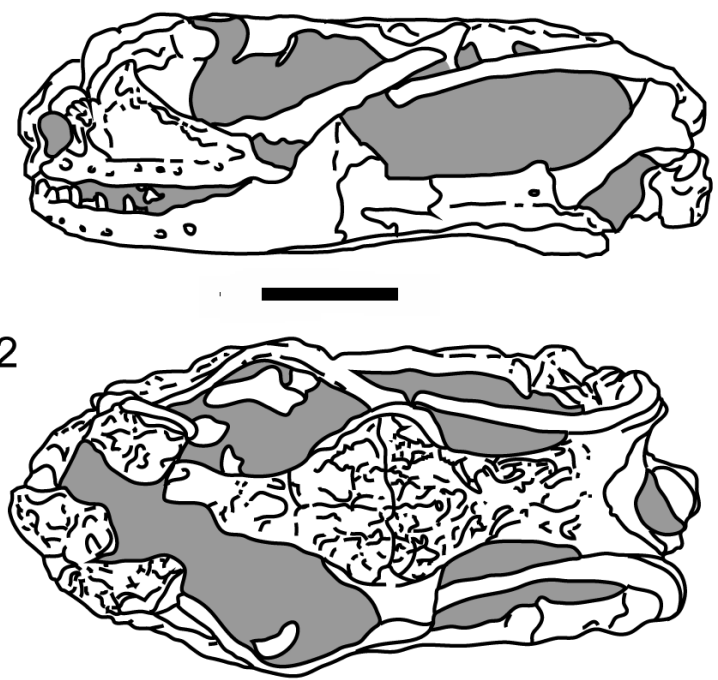

3

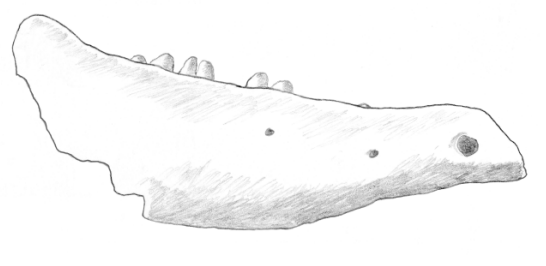

$1 \mathrm{~mm}$

4
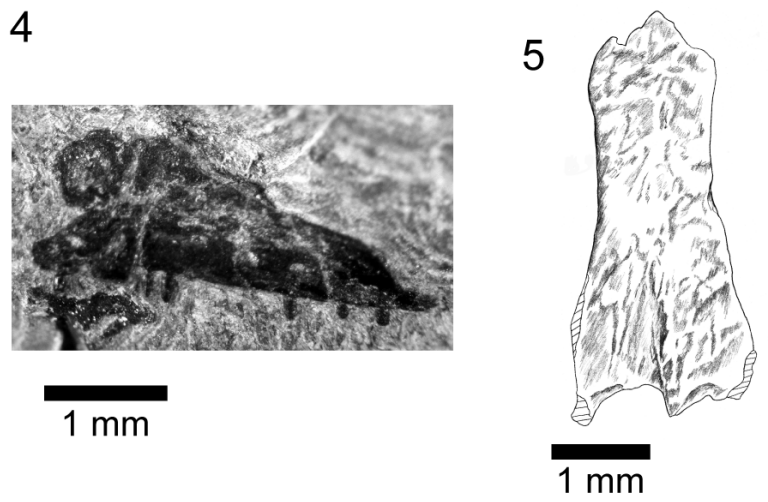

FIGURE 17. Comparison of Shiramine Morphotype B and Myrmecodaptria microphagosa (Gao and Norell, 2000) from the Late Cretaceous of Mongolia. 1-2, left lateral and dorsal views respectively of the skull of Myrmecodaptria microphagosa, redrawn from $\mathrm{Gao}$ and Norell (2000). Scale bar equals $5 \mathrm{~mm} ; 3$, dentary of morphotype B, SBEI 827, labial view; 4 , isolated left maxilla, SBEI 2407, in labial view; 5, isolated median frontal, SBEI 1803, in dorsal view.
Kuroyuriella mikikoi, and Sakurasaurus shokawensis all have paired frontals, and their larger size precludes their paired condition being a juvenile feature. SBEI 1803 is also too small for either the long-bodied Kaganaias hakusanensis or the borioteiioid Kuwajimalla kagaensis, but again it resembles the frontal of Myrmecodaptria microphagosa and could pertain to Shiramine morphotype B.

Whether these elements belong to a single taxon, and whether that taxon is related to Mymecodaptria, remains speculative pending recovery of more complete material.

\section{SQUAMATA Oppel, 1811 \\ Family indet. \\ Morphotype C \\ Figure 18}

Material. Many of the other isolated lizard maxillae and dentaries in the Shiramine collection can be attributed to Sakurasaurus, which is the most common lizard taxon at this locality. However, SBEI 1277 (Li177) is the posterior end of a deep (2.25 $\mathrm{mm}$ ) left dentary preserved in labial view and bearing seven teeth with spaces for 4-5 others (Figure 18).

Description. The jaw is characterised by a deep posterior incisure that extends anteriorly below the end of the tooth row, and in having teeth that are very small in relation to the height of the jaw (tooth height/jaw height $0.08-0.11$ v. 0.21-0.34 in other small Tetori lizards). It does not match any of the named Shiramine taxa, and seems to represent yet another squamate morphotype, but is too fragmentary for further identification. In the deep posterior incisure, it resembles some of the "scincomorph" dentaries described by Ikeda and Saegusa (2013) from the Sasayama Group, but the teeth of the Tetori lizard are relatively much smaller.

\section{SQUAMATA Oppel, 1811 Family indet.}

In addition to the two partial postcranial skeletons that may pertain to Asagaolacerta tricuspidens, the Shiramine material includes further isolated postcranial elements. A large proportion of the vertebrae can be attributed to the long-bodied Kaganaias hakusanensis (Evans et al., 2006), but smaller ones include: SBEI 292 (Li157), the anterior part of an autotomous caudal vertebra; SBEI 831 (Li104), a procoelous vertebra with a rounded condyle and no zygosphenes; and SBEI 833 (Li106), a fragmentary vertebra with small zygapophyses and a more dorsoventrally depressed condyle. These vertebrae are difficult to attribute 
1

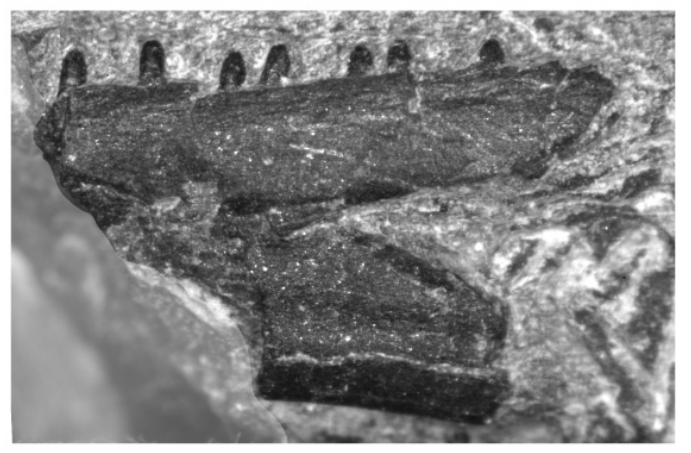

$1 \mathrm{~mm}$

2

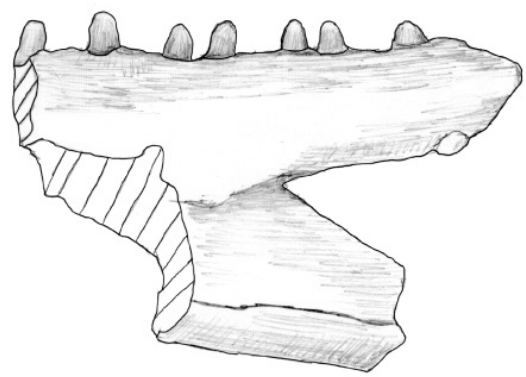

FIGURE 18. Shiramine Morphotype C, SBEI 1277, posterior region of a left dentary in 1-2, labial view.

but presumably belong to one or more of the small lizards described above.

In addition to the vertebrae, the most common postcranial elements are osteoderms (e.g., SBEI 200-226, 247-255, 276, 556, 559-61, 563, 565, 568-69, 571-79, 807, 811-813, 819, 839-841, 857, $865-883$, 893-899, 1218-1220, 1230, 1280-81, 1296-97, 1299-1300, 1509, 1523, 1516-17, 1539, $1544,1547,1560,1564,1580,1584,1586$, $1594,1599,1634,1640,1648,1671-73,1694$, $1715,1723,1728,1731,1741,1804-1806)$, preserved either individually or in groups. These osteoderms are all of the same type. They are rectangular and broadly resemble the osteoderms of paramacellodid lizards (e.g., Paramacellodus spp., Becklesius spp., Sharovisaurus karatauensis, Mimobecklesisaurus gansuensis) from the Late Jurassic and Early Cretaceous of Europe (e.g., Guimarota, Portugal; Purbeck Limestone Group of England: Hoffstetter, 1966; Estes, 1983; Bro- schinski, 2000; Evans, personal observation); Asia (e.g., Transbaikalian Russia: Averianov and Fayngertz, 2001; Averianov and Skutschas, 1999; Kazakhstan: Hecht and Hecht, 1984; China: Li, 1985); and North America (e.g., Morrison Formation: Evans and Chure,1998). However, the Tetori osteoderms are too large to belong to any of the lizard taxa described herein and none of the lizard specimens from the Tetori deposits preserves osteoderms in association with other skeletal material. They therefore remain something of a mystery.

\section{DISCUSSION}

The small lizard specimens described herein add a minimum of five taxa to the Tetori squamate assemblage: Asagaolacerta tricuspidens, Kuroyuriella mikikoi, Hakuseps imberis, the second bicuspid form (Morphotype A), and the Myrmecodaptrialike Morphotype B (SBEI 827), with the potential of at least one other, the lizard represented by SBEI 1277 (Morphotype C). The latter three cannot be named without more suitable type material, but with the previously described. Sakurasaurus sp. (Evans and Manabe, 2009), Kaganaias hakusanensis (Evans et al., 2006), and Kuwajimalla kagaensis (Evans and Manabe, 2008), the new material places eight or nine different lizard taxa in the Tetori deposits at Shiramine. Sakurasaurus shokawensis and bones of one or more unnamed taxa are known from roughly contemporaneous deposits at Shokawa (Evans and Manabe, 1999a). Moreover, new squamate material has recently been recovered from slightly younger (early Albian) deposits in Hyogo Prefecture. In addition to the Pachygenys adachii jaw mentioned above (Ikeda et al., 2015), the "Lower Formation" of the Sasayama Group in Hyogo Prefecture has yielded several isolated "scincomorph" dentaries (Ikeda and Saegusa, 2013). One of these (Hyogo Type A) shows some resemblance to Sakurasaurus shokawensis, but the others are distinct and show no obvious affinity to the taxa described herein in their combination of dental and mandibular characters.

At the time of Tetori Group deposition, Japan lay on the eastern edge of the Asian continent, adjacent to what is now the Korean Peninsula and north eastern China. Earlier age estimates for the Kuwajima and Okurodani formations suggested they were significantly older than the Jehol deposits, but the new age estimates for these Tetori Group horizons have largely removed the age gap. The relative age and geographical proximity of the Japanese and Chinese assemblages is reflected 
by the presence of some shared, or closely related, taxa, notably of fish (Yabumoto, 2000, 2014), choristoderan reptiles (Evans and Manabe, 1999a; Matsumoto et al., 2007, 2014), and multituberculate mammals (Kusuhashi, 2008). As yet, only two of the Japanese lizard genera are known to be closely related to Chinese taxa. One is Pachygenys, originally described from Shandong Province, China (Gao and Cheng, 1999). The other is Sakurasaurus, which seems to be the sister taxon of the Jehol (Yixian and Jiufotang Fm) genus Yabeinosaurus (Evans et al., 2005; Evans and Manabe, 2009; Evans and Wang, 2012). However, others of the Tetori assemblage may represent lineages that came to dominate Asia (Mongolia, China) in the Late Cretaceous (e.g., Alifanov, 2000a, 2000b; Gao and Norrell, 2000), most notably the borioteiioids. The multicuspidate Kuwajimalla kagaensis was interpreted as an early borioteiioid (Evans and Manabe, 2008), and this group is now also represented in Japan by Asagaolacerta tricuspidens.

Borioteiioids were also highly successful in the Late Cretaceous of North America, mainly in the form of the large, broad-toothed Polyglyphanodon sternbergi and the smaller chamopsiids and chamopsiid-like taxa (as discussed above). The first records of borioteiioids in North America date from the Coniacian (Longrich et al., 2012), and it seems likely that this group entered North America from Asia when the Bering Strait land bridge opened in the Aptian-Albian or Albian-Cenomanian (both dates have been proposed, Zanno and Makovicky, 2011). Kuwajimalla kagaensis is already specialised, but Asagaolacerta tricuspidens may be closer to the ancestral borioteiioid morphotype. Borioteiioids have also been reported from the Aptian-Albian deposits of Höovor, Mongolia (Alifanov, 1993), although none has teeth like Asagaolacerta.

The remaining Kuwajima Formation lizards include the bizarre Hakuseps imberis, the tantalising Myrmecodaptria-like Morphotype $\mathrm{B}$, and the problematic Kuroyuriella mikikoi. The stem squamate placement of the latter taxon seems likely to be due to 'stemward slippage' (sensu Sansom et al., 2010), with too few definitive characters available for coding. A stem-scincid position was recovered with Implied Weighting, and is more consistent with the preserved characters, but must be regarded as provisional at best. Most recent molecular analyses have recognised the monophyly of Scincidae and many place its origin in the Jurassic, 175 Ma (e.g., Kumazawa, 2007; Albert et al., 2008; Vidal and Hedges, 2009). Wiens et al. (2006) estimated that stem scincids separated from cordyliforms and xantusiids in the Late Jurassic ( 155 Ma), with crown-group scincids diversifying in the Late Cretaceous from around $95 \mathrm{Ma}$. Jones et al. (2013) obtained a similar date for the diversification of crown-scincids but placed the origin of the scincid stem in the Early Cretaceous ( 135 Ma). The Mesozoic record of scincids is surprisingly poor and reported occurrences are limited to isolated jaws from the Late Jurassic (Kimmeridgian) of Guimarota, Portugal (Kosma, 2004) and the Late Cretaceous (Campanian) of North America (Gao and Fox, 1996), with possible scincoids from the Early Cretaceous of Mexico (Tepexisaurus tepexii, Reynoso and Callison, 2000) and Utah (Nydam, 2002). The least derived genera of extant scincids (the "Eumeces group") are found in Northern continents (Eastern Asia, North America), leading Greer (1970) to suggest an Old World origin of scincids, with later entry into North America via the Bering Strait land bridge. Nydam (2002) made a similar inference. The reported presence of Slavoia-like stem-scincids in the Aptian-Albian of Mongolia (Höövör: Alifanov, 2000a), as well as the Late Cretaceous of the same region (Gao and Norell, 2000), would be consistent with this hypothesis, as would a stem-scincid from the Barremian-Aptian of Japan.

The long-bodied, putative mosasauroid Kaganaias hakusanensis (Evans et al., 2006) was probably at least semi-aquatic. Unlike the Jehol Biota, where the shinisaur or stem-shinisaur Dalinghosaurus longidigitus is relatively common, terrestrial anguimorphs have yet to be recovered from Japan unless the parietal recovered from Shokawa (Evans and Manabe, 1998) belongs to a representative of this group. Moreover, neither lizard fauna contains any certain representation of iguanians, despite their reported presence in the Early Cretaceous (Aptian-Albian) of Mongolia (Alifanov, 2000a) and Central Asia (Kirghizia, Uzbekistan, Kazakhstan: Nessov, 1988; Gao and Nessov, 1998), and the Late Cretaceous (e.g., Gao and Hou, 1995, 1996; Gao and Norell, 2000) of both China and Mongolia. The Jehol gliding lizard Xianglong zhaoi was interpreted as an acrodont iguanian (Li et al., 2007), but its skull and dentition are too poorly preserved for confident attribution (Evans, personal observation), and adult material needs to be recovered.

It is clear that western Japan in the Barremian-Aptian hosted a rich and diverse lizard assemblage of herbivores (Kuwajimalla), insecti- 
vores (Hakuseps, Kuroyuriella, Asagoalacerta, Morphotype A, Sakurasaurus, and the Sasayama Group lizards), and small carnivores (Kaganaias). Although many remain difficult to place in a phylogeny, they seem to include freshwater mosasauroids (Kaganaias) and terrestrial borioteiioids or stem-borioteiioids (Asagaolacerta, Kuwajimalla). At least some have relatives or congenerics in China (Pachygenys, Sakurasaurus). Together with the anatomically more complete, but currently less diverse, Jehol lizard assemblage, these taxa provide an indication of squamate diversity in Asia at an important time in its history - presaging the Late Cretaceous Asian lizard diversity that is far better known (e.g., Alifanov, 2000a, 2000b; Gao and Norell, 2000). Moreover, if the Bering Strait land bridge opened up in Aptian-Albian or Albian-Cenomanian times, then these Early Cretaceous Asian lizard faunas may include the ancestors of some later North American clades.

\section{CONCLUSIONS}

Lizard assemblages from the Late Cretaceous of eastern Asia are exceptionally rich and diverse, with representatives of pleurodont and acrodont iguanians; monstersaur, shinisaur and varanoid anguimorphs; scincoids; and a wide range of borioteiioids. Our knowledge of the antecedent faunas of the same region remains incomplete, but over the last two decades, Chinese, Mongolian, and Japanese localities have gradually begun to fill some of the gaps. The Japanese lizard specimens from the Kuwajima Formation are more fragmentary than specimens from the Yixian and Jiufotang Formations of China, but they make an important contribution in providing the earliest records of borioteiioids, a group that subsequently radiated in both Asia and North America.

\section{ACKNOWLEDGEMENTS}

This work began during Royal Society-Japan Society for the Promotion of Science funded joint projects coordinated by S.E. Evans and M. Manabe. To M. Manabe we extend our thanks for his collegiality, and continued support and encouragement over almost two decades. Research on the faunal assemblage at Shiramine was initiated by I. Yamaguchi and later continued by T. Sakumoto, T. Hibino, T. Sonoda, and K. Otsuka, with much of the exquisite and delicate preparation by M. Yamaguchi, S. Isaji, H. Matsuoka, and, more recently, A. Wakimoto (dentary of Hakuseps). Work on the Kaseki-Kabe assemblage has been sup- ported by the Shiramine Board of Education and, more recently, the Board of Education for Hakusan City, notably H. Imai and Y. Kobarashi. To them we express our gratitude. The work was also funded in part by Japan Society for the Promotion of Science (JSPS) grants 12800018 (2000-2003) and 15340179 (2003-2006) to M. Manabe. The Hakuseps specimen was found by a young school student, Teruko Ueno, during an Excavation Experience course at the Natural History Museum and Institute, Chiba, in 2003. Other materials were collected during fieldwork and subsequent preparation. The authors thank S. Isaji, Natural History Museum and Institute, Chiba, Japan, for discussion of geology, and Y. Wang, Institute of Vertebrate Paleontology and Paleoanthropology, Beijing, P.R.China, for access to Jehol lizard specimens. We also thank J. Daza, Villanova University, USA, for comments on an earlier version of the manuscript, for discussion of gekkotan fossils, for help with aspects of the phylogenetic analysis, and for supplying the 'minisearch' macro developed by $\mathrm{S}$. Arias (INSUE, Universidad Nacional de Tucumán, Argentina). The Willi Hennig Society is acknowledged for making TNT freely available to researchers. The digital images used in this paper were mostly taken by M. Okura (Aichi Prefecture, Japan).

\section{REFERENCES}

Albert, E.M., San Mauro, D., García-París, M., Rüber, L., and Zardoya, R. 2008. Effect of taxon sampling on recovering the phylogeny of squamate reptiles based on complete mitochondrial genome and nuclear gene sequence data. Gene, 441:12-21.

Alifanov, V.R. 1989 The oldest gecko (Lacertilia, Gekkonidae) from the Lower Cretaceous of Mongolia. Paleontologicheskii Zhurnal, 1989:124-126. (In Russian)

Alifanov, V. R. 1990. The oldest gecko (Lacertilia, Gekkonidae) from the Lower Cretaceous of Mongolia. Paleontological Journal, 23:128-131. (English translation of Alifanov, 1989)

Alifanov, V.R. 1993. Some peculiarities of the Cretaceous and Palaeogene lizard faunas of the Mongolian People's Republic. Kaupia, 3:9-13.

Alifanov, V.R. 2000a. The fossil record of Cretaceous lizards from Mongolia, p. 368-389. In Benton, M.J., Shishkin, M.A., Unwin, D.M., and Kurochkin, E.N. (eds.), The Age of Dinosaurs in Russia and Mongolia. Cambridge University Press, Cambridge.

Alifanov, V.R. 2000b. Macrocephalosaurs and the early evolution of lizards of Central Asia. Trudi Paleontologicheskoyo Instituta, 272:1-126. (In Russian)

Andres, B. and Norell, M.A. 2005. The first record of a pterosaur from the Lower Cretaceous sediments of 
Öösh (Omnogov: Mongolia). American Museum Novitates, 3472:1-6.

Averianov, A.O. and Fayngertz, A.V. 2001. Lizards of the Early Cretaceous of Western Siberia, p. 6-8. In Ananjeva, N.B. (ed.), Questions of Herpetology. Materials of the First Congress of the A.M. Nikol'skii Herpetological Society. Pushchino-Moskva MGU. (In Russian with English summary)

Averianov, A.O. and Skutschas, P.P. 1999. Paramacellodid lizard (Squamata, Scincomorpha) from the Early Cretaceous of Transbaikalia. Russian Journal of Herpetology, 6:115-117.

Azuma, Y. and Tomida, Y. 1995. Early Cretaceous dinosaur fauna of the Tetori Group in Japan, p.125-131. In Sun, A. and Wang, Y. (eds.), Sixth Symposium on Mesozoic Terrestrial Ecosystems and Biota, Short papers. China Ocean Press, Beijing.

Barahona, F. and Green, B. 1997. Postnatal ontogeny of the dentition in lacertid lizards, p.13. In Roček, Z. and Hart, S. (eds.), Herpetology 97, Abstracts of the Third World Congress of Herpetology, Prague.

Bhullar, B-A. S. 2010. Cranial osteology of Exostinus serratus (Squamata: Anguimorpha), fossil sister taxon to the enigmatic clade Xenosaurus. Zoological Journal of the Linnean Society, 159:921-953.

Bolet, A. and Evans, S.E. 2010. A new lizard from the Early Cretaceous of Catalonia (Spain), and the Mesozoic lizards of the Iberian Peninsula. Cretaceous Research, 31:447-457.

Bolet, A. and Evans, S.E. 2011. New material of the enigmatic Scandensia, an Early Cretaceous lizard from the Iberian Peninsula. Special Papers in Palaeontology, 86:99-108.

Borsuk-Białynicka, M. 1985. Carolinidae, a new family of xenosaurid-like lizards from the Upper Cretaceous of Mongolia. Acta Palaeontologica Polonica, 30:151176.

Borsuk-Białynicka, M. 1990. Gobekko cretacicus gen. et sp. n., a new gekkonid lizard from the Cretaceous of the Gobi Desert. Acta Palaeontologica Polonica, 35:67-76.

Bremer K. 1994. Branch support and tree stability. Cladistics, 10:295-304.

Broschinski, A. 2000. The lizards from the Guimarota mine, p. 59-68. In Martin, T. and Krebs, B. (eds.), Guimarota, a Jurassic Ecosystem. Verlag Dr Friedrich Pfeil, München.

Chang, M., Chen, P., Wang, Y., and Wang, Y. 2003. The Jehol Biota: Emergence of Feathered Dinosaurs and Beaked Birds. Shanghai Scientific and Technical Publishers, Shanghai, China.

Chang, S., Zhang, H., Renne, P.R., and Fang, Y. 2009. High precision ${ }^{40} \mathrm{Ar} /{ }^{39} \mathrm{Ar}$ age for the Jehol Biota. Palaeogeography, Palaeoclimatology, Palaeoecology, 280:94-104.

Conrad, J. 2008. Phylogeny and systematics of Squamata (Reptilia) based on morphology. Bulletin of the American Museum of Natural History, 310:1-182.
Conrad, J. and Norell, M.A. 2006. High-resolution X-ray computed tomography of an Early Cretaceous gekkonomorph (Squamata) from Öösh (Övörkhangai, Mongolia). Historical Biology, 18:405-431.

Daza, J.D., Alifanov, V.R., and Bauer, A.M. 2012. A redescription and phylogenetic reinterpretation of the fossil lizard Hoburogekko suchanovi Alifanov, 1989 (Squamata, Gekkota), from the Early Cretaceous of Mongolia. Journal of Vertebrate Paleontology, 32:1303-1312.

Daza, J.D., Bauer, A.M., and Snively, E.D. 2013. Gobekko cretacicus (Reptilia: squamata) and its bearing on the interpretation of gekkotan affinities. Zoological Journal of the Linnean Society, 167:430448.

Daza, J.D., Bauer, A.M., and Snively, E.D. 2014. On the fossil record of the Gekkota. Anatomical Record, 297:433-462.

Denton, R.K. and O'Neill, R.C. 1995. Prototeius stageri, gen. et sp. nov., a new teiid lizard from the Upper Cretaceous Marshaltown Formation of New Jersey, with a preliminary phylogenetic revision of the Teiidae. Journal of Vertebrate Paleontology, 15:235-253.

Estes, R. 1964. Fossil vertebrates from the Late Cretaceous Lance Formation eastern Wyoming. University of California Publications in Geological Science, 49:1-180.

Estes, R., 1983. Sauria Terrestria, Amphisbaenia, p.1245. In Wellnhofer, P. (ed.), Handbuch der Paläoherpetologie, 10A. Gustav Fischer Verlag, Stuttgart.

Estes, R., De Queiroz, K., and Gauthier, J. 1988. Phylogenetic relationships within Squamata, p.119-281. In Estes, R. and Pregill, G. (eds.). Phylogenetic Relationships of the Lizard Families. Stanford University Press, Stanford.

Evans, S.E. 2008. The skull of lizards and Tuatara, p.1347. In Gans, C., Gaunt, A.S., and Adler, K. (eds.), Biology of the Reptilia, Vol. 20, The Skull of Lepidosauria. Society for the Study of Amphibians and Reptiles, Ithaca, New York.

Evans, S.E. and Barbadillo, L.J. 1997. Early Cretaceous lizards from las Hoyas, Spain. Zoological Journal of the Linnean Society, 119:23-49.

Evans, S.E. and Chure, D. 1998. Paramacellodid lizard skulls from the Jurassic Morrison Formation at Dinosaur National Monument, Utah. Journal of Vertebrate Paleontology, 18:99-114.

Evans, S.E. and Manabe, M. 1998. Early Cretaceous frog remains from the Okurodani Formation, Tetori Group, Japan. Paleontological Research, 2:275-278.

Evans, S.E. and Manabe, M. 1999a. Early Cretaceous lizards from the Okurodani Formation of Japan. Geobios, 32:889-899.

Evans, S.E. and Manabe, M. 1999b. A choristoderan reptile from the Lower Cretaceous of Japan. Special Papers in Palaeontology, 60:101-119.

Evans, S.E. and Manabe, M. 2000. Fossil lizards, p.105106. In Matsuoka, H. (ed.), Fossils of the Kuwajima 
'Kaseki-kabe' (Fossil-bluff). Scientific Report on a Neocomian (Early Cretaceous) Fossil Assemblage from the Kuwajima Formation, Tetori Group, Shiramine, Ishikawa, Japan. Shiramine Village Board of Education, Ishikawa Prefecture, Japan. (In Japanese with English abstract)

Evans, S.E. and Manabe, M. 2008. A herbivorous lizard from the Early Cretaceous of Japan. Palaeontology, 51:487-498.

Evans, S.E. and Manabe, M. 2009. The Early Cretaceous lizards of eastern Asia: new material of Sakurasaurus from Japan. Special Papers in Palaeontology, 81:43-59.

Evans, S.E., Manabe, M., Cook, E., Hirayama, R., Isaji, S., Nicholas, C.J., Unwin, D., and Yabumoto, Y. 1998. An Early Cretaceous assemblage from Gifu Prefecture, Japan. Bulletin of the New Mexico Museum of Natural History and Science, 14:183-186.

Evans, S.E., Manabe, M., Noro, M., Isaji, S., and Yamaguchi, M. 2006. A long-bodied lizard from the Cretaceous of Japan. Palaeontology, 49:1143-1165.

Evans, S.E. and Searle, B. 2002. The lepidosaurian assemblage of the Purbeck Limestone Group. Special Papers in Palaeontology, 68:145-159.

Evans, S.E. and Wang, Y. 2005. The Early Cretaceous Dalinghosaurus from China. Acta Palaeontologica Polonica, 50:725-742.

Evans, S.E. and Wang, Y. 2010. A new lizard (Reptilia: Squamata) with exquisite preservation of soft tissue from the Lower Cretaceous of Inner Mongolia, China. Journal of Systematic Palaeontology, 8:81-95.

Evans, S.E. and Wang, Y. 2012. New material of the Early Cretaceous lizard Yabeinosaurus from China. Cretaceous Research, 34:48-60.

Evans, S.E., Wang, Y., and Li, C. 2005. The Early Cretaceous lizard Yabeinosaurus from China: resolving an enigma. Journal of Systematic Palaeontology, 3:319335.

Fujita, M. 2003. Geological age and correlation of the vertebrate-bearing horizons in the Tetori Group. Memoir of the Fukui Prefectural Dinosaur Museum, 2:3-14.

Gao, K. and Cheng, Z. 1999. A new lizard from the Lower Cretaceous of Shandong, China. Journal of Vertebrate Paleontology, 19:456-465.

Gao, K. and Fox, R.C. 1996. Taxonomy and evolution of Late Cretaceous lizards (Reptilia: Squamata) from western Canada. Bulletin of the Carnegie Museum of Natural History, 33:1-107.

Gao, K. and Hou, L. 1995. Iguanians from the Upper Cretaceous Djadochta Formation, Gobi Desert, China. Journal of Vertebrate Paleontology,15:57-78.

Gao, K. and Hou, L. 1996. Systematics and diversity of squamates from the Upper Cretaceous Djadochta Formation, Bayan Mandahu, Gobi Desert, People's Republic of China. Canadian Journal of Earth Sciences, 33:578-598.

Gao, K. and Nessov, L.A. 1998. Early Cretaceous squamates from the Kyzylkum Desert, Uzbekistan. Neues
Jahrbüch für Geologische und Paläontologische Abhandlungen, 207: 289-309.

Gao, K. and Norell, M.A. 2000. Taxonomic composition and systematics of Late Cretaceous lizard assemblages from Ukhaa Tolgod and adjacent localities, Mongolian Gobi Desert. American Museum of Natural History Bulletin, 249:1-118.

Gauthier, J., Kearney, M., Maisano, J.A., Rieppel, O., and Behlke, A.D.B. 2012. Assembling the squamate tree of life: perspectives from the phenotype and the fossil record. Bulletin of the Peabody Museum of Natural History, 53:3-308.

Gifu-Ken Dinosaur Research Group 1992. The Tetori Group in Ogamigo area, Shokawa-mura, Gifu Prefecture, Japan. Bulletin of the Gifu Prefectural Museum, 13:9-16. (In Japanese)

Goloboff, P.A. 1999. Analyzing large data sets in reasonable times: Solutions for composite optima. Cladistics, 15:415-428.

Goloboff, P.A., Farris, J.S., and Nixon, K.C. 2003. T.N.T.: tree analysis using new technology, V. 1.0., downloaded February 2015. www.zmuc.dk/public/phylogeny

Goloboff, P.A., Farris, J.S., and Nixon, K.C. 2008. TNT, a free program for phylogenetic analysis. Cladistics, 24:774-786.

Gradstein, F.M. and Ogg, J.G. 2004. Geologic time scale 2004, why, how, and where next? Lethaia, 37:175181.

Greer, A.M. 1970. A subfamilial classification of scincid lizards. Bulletin of the Museum of Comparative Zoology, Harvard, 139:151-183.

Hasegawa, Y., Manabe, M., Isaji, S., Ohkura, M., Shibata, I., and Yamaguchi, I. 1995. Terminally resorbed iguanodontid teeth from the Neocomian Tetori Group, Ishikawa and Gifu Prefecture, Japan. Bulletin of the National Science Museum, Tokyo, Series C, 21:3549.

Hecht, M.K. and Hecht, B.M. 1984. A new lizard from Jurassic deposits of Middle Asia. Paleontologicheskii Zhurnal, 3:135-138.

Hirayama, R. 1996. Fossil land turtles from the Early Cretaceous of Central Japan. Journal of Vertebrate Paleontology, 16(Supplement to 3):41A.

Hirayama, R. 1999. Testudinoid turtles from the Early Cretaceous (Neocomian) of Central Japan. Journal of Vertebrate Paleontology, 19(Supplement to 3):51$52 \mathrm{~A}$.

Hirayama, R. 2000. Fossil turtles, p.75-92. In Matsuoka, $\mathrm{H}$. (ed.), Fossils of the Kuwajima 'Kaseki-kabe' (Fossil-bluff). Scientific report on a Neocomian (Early Cretaceous) Fossil Assemblage from the Kuwajima Formation, Tetori Group, Shiramine, Ishikawa, Japan. Shiramine Village Board of Education, Ishikawa Prefecture, Japan. (In Japanese with English abstract)

Hoffstetter, R. 1966. Les Sauria (=Lacertilia) du Jurassique supérieur du Montsech (Espagne). Bulletin de la Societe Géologique de France, 7:549-557. 
Hoffstetter, R. 1967. Coup d'oeil sur les Sauriens (Lacertiliens) des couches de Purbeck (Jurassique supérieur d'Angleterre). Problèmes Actuels de Paléontologie (Evolution des Vertébrés) Centre National de la Recherche Scientifique, 163:349-371.

Ikeda, T., Ota, H., and Saegusa, H. 2015. A new fossil lizard from the Lower Cretaceous Sasayama Group of Hyogo prefecture, western Honshu, Japan. Journal of Vertebrate Paleontology, 35:e885032.

Ikeda, T. and Saegusa, H. 2013. Scincomorphan lizards from the Lower Cretaceous Sasayama Group, Hyogo, Japan. Journal of Fossil Research, 46:2-14.

Isaji, S., Okasaki, H., Hirayama, R., Matsuoka, H., Barrett, P., Tsubamoto, T., Yamaguchi, M., Yamaguchi, I., and Sakumoto, T. 2005. Depositional environments and taphonomy of the bone-bearing beds of the Lower Cretaceous Kuwajima Formation, Tetori Group, Japan. Bulletin of the Kitakyushu Museum of Natural History and Human History, Series A Natural History, 3:123-133.

Ji, S. and Ji, Q. 2004. Postcranial anatomy of the Mesozoic Dalinghosaurus (Squamata): evidence from a new specimen of western Liaoning. Acta Geologica Sinica, 78:897-906.

Jones, M.E.H., Anderson, C.L, Hipsley, C.A., Müller, J., Evans, S.E., and Schoch, R.S. 2013. Integration of molecules and new fossils supports a Triassic origin for Lepidosauria (lizards, snakes, and tuatara). BMC Evolutionary Biology (Section: Phylogenetics and Phylogeography), 13:208. doi:10.1186/1471-214813-208

Kley, N. 2004. The Deep Scaly Project, "Leptotyphlops dulcis" (Online), Digital Morphology. Accessed July 4th, 2014, at http://digimorph.org/specimens/Leptotyphlops dulcis/

Kosma, R. 2004. The Dentitions of Recent and Fossil Scincomorphan Lizards (Lacertilia, Squamata): Systematics, Functional Morphology, Palecology. Ph.D. Thesis, University of Hannover. Digital publication, University of Hannover website: www.tib.uni-hannover.de/Digitale Bibliothek/Elektronische Hochschulschriften.html

Kumazawa ${ }_{\perp}$ Y. 2007 Mitochondrial genomes from major lizard families suggest their phylogenetic relationships and ancient radiations. Gene, 388:19-26.

Kusuhashi, N. 2008. Early Cretaceous multituberculate mammals from the Kuwajima Formation (Tetori Group), Central Japan. Acta Palaeontologica Polonica, 53:379-390.

Kusuhashi, N., Matsuoka, H., Kamiya, H., and Setoguchi, T. 2002. Stratigraphy of the late Mesozoic Tetori Group in the Hakusan Region, central Japan: an overview. Memoirs of the Faculty of Science, Kyoto University, Geology and Mineralogy Series, 59:9-31.

Kusuhashi, N., Matsumoto, A., Murakami, M., Tagami, T., Hirata, T., lizuka, T., Handa, T., and Matsuoka, H. 2006. Zircon $\mathrm{U}-\mathrm{Pb}$ ages from tuff beds of the upper Mesozoic Tetori Group in the Shokawa district, Gifu
Prefecture, central Japan. The Island Arc, 15:378390.

Kusuhashi, N., Tsutsumi, Y., Seagusa, H., Horie, K., Ikeda, T., Yokoyama, K., and Shiraishi, K. 2013. A new Early Cretaceous eutherian mammal from the Sasayama Group, Hyogo, Japan. Proceedings of the Royal Society B, 280(1759). doi: 10.1098/ rspb.2013.0142

Li, J. 1985. A new lizard from the Late Jurassic of Subei, Gansu. Vertebrata PalAsiatica, 23: 13-18. (In Chinese with English summary)

Li, P., Gao, K., Hou, L., and Xu, X. 2007. A gliding lizard from the Early Cretaceous of China. Proceedings of the National Academy of Sciences of the United States of America, 104:5507-5509.

Longrich, N.A., Bhullar, B.A., and Gauthier, J.A. 2012. Mass extinction of lizards and snakes at the Cretaceous-Paleogene boundary. Proceedings of the National Academy of Sciences of the United States of America, 109:21396-21401.

Maeda, S. 1961. On the geological history of the Mesozoic Tetori Group in Japan. Journal of the College of Arts and Science, Chiba University, 3:369-426. (In Japanese with English abstract)

Manabe, M. 1999. The early history of the Tyrannosauridae in Asia. Journal of Paleontology, 13:477-482.

Manabe, M. and Barrett, P.M. 2000. Dinosaurs, p.93-98. In Matsuoka, H. (ed.), Fossils of the Kuwajima 'Kaseki-kabe' (Fossil-bluff). Scientific Report on a Neocomian (Early Cretaceous) Fossil Assemblage from the Kuwajima Formation, Tetori Group, Shiramine, Ishikawa, Japan. Shiramine Village Board of Education, Ishikawa Prefecture, Japan. (In Japanese with English abstract)

Manabe, M., Rougier, G.W., Isaji, S., and Matsuoka, H. 2000a. Fossil mammals, p.107-108. In Matsuoka, H. (ed.), Fossils of the Kuwajima 'Kaseki-kabe' (Fossilbluff). Scientific Report on a Neocomian (Early Cretaceous) Fossil Assemblage from the Kuwajima Formation, Tetori Group, Shiramine, Ishikawa, Japan. Shiramine Village Board of Education, Ishikawa Prefecture, Japan. (In Japanese with English abstract)

Manabe, M., Barrett, P.M., and Isaji, S. 2000b. A refugium for relicts? Nature, 404:953.

Matsukawa, M. and Obata, I. 1994. Dinosaurs and sedimentary environments in the Japanese Cretaceous: a contribution to dinosaur facies in Asia based on molluscan palaeontology and stratigraphy. Cretaceous Research, 15:101-125.

Matsumoto, R., Evans, S.E., and Manabe, M. 2007. Monjurosuchus (Reptilia: Choristodera) from the Lower Cretaceous of Japan. Acta Palaeontologica Polonica, 52:329-350.

Matsumoto, R., Evans, S.E., and Shimojima, S. 2002. The dentary of a choristodere (Reptilia: Archosauromorpha) from the Okurodani Formation, Tetori Group (Early Cretaceous), Japan. Bulletin of the National Science Museum, Tokyo, 28:43-48. 
Matsumoto, R., Manabe, M., and Evans, S.E. 2014. The first record of a long-snouted choristodere (Reptilia, Diapsida) from the Early Cretaceous of Ishikawa Prefecture, Japan. Historical Biology, 27:109-114.

Matsuoka, H. 2000a. A frog fossil, p.50-52. In Matsuoka, $\mathrm{H}$. (ed.), Fossils of the Kuwajima 'Kaseki-kabe' (Fossil-bluff). Scientific report on a Neocomian (Early Cretaceous) fossil assemblage from the Kuwajima Formation, Tetori Group, Shiramine, Ishikawa, Japan. Shiramine Village Board of Education, Ishikawa Prefecture, Japan. (In Japanese)

Matsuoka, H. 2000b. Tritylodonts (Synapsida, Therapsida), p.53-74. In Matsuoka, H. (ed.), Fossils of the Kuwajima 'Kaseki-kabe' (Fossil-bluff). Scientific Report on a Neocomian (Early Cretaceous) Fossil Assemblage from the Kuwajima Formation, Tetori Group, Shiramine, Ishikawa, Japan. Shiramine Village Board of Education, Ishikawa Prefecture, Japan. (In Japanese)

Müller, J., Hipsley, C.A., Head, J.J., Kardjilov, N., Hilger, A., Wuttke, M., and Reisz, R.R. 2011. Eocene lizard from Germany reveals amphisbaenian origins. Nature, 473:364-367.

Nessov, L.A. 1988. Late Mesozoic amphibians and lizards of Soviet Middle Asia. Acta Zoologica Cracoviensia, 31:475-486.

Nydam, R.L. 2002. Lizards of the Mussentuchit local fauna (Albian-Cenomanian boundary) and comments on the evolution of the Cretaceous lizard fauna of North America. Journal of Vertebrate Paleontology, 22:645-600.

Nydam, R.L., Caldwell, M.W., and Fanti, F. 2010. Borioteiioidean lizard skulls from Kleskun Hill (Wapiti Formation; upper Campanian), west-central Alberta, Canada. Journal of Vertebrate Paleontology, 30:1090-1099.

Nydam, R.L. and Cifelli, R.L. 2002a A new teiid lizard from the Cedar Mountain Formation (Albian-Cenomanian boundary) of Utah. Journal of Vertebrate Paleontology, 22:276-285.

Nydam, R.L. and Cifelli, R.L. 2002b. Lizards from the Lower Cretaceous (Aptian-Albian) Antlers and Cloverly Formations. Journal of Vertebrate Paleontology, 22:286-298.

Nydam, R.L., Eaton, J.G., and Sankey, J. 2007. New taxa of transversely-toothed lizards (Squamata: Scincomorpha) and new information on the evolutionary history of 'teiids'. Journal of Vertebrate Paleontology, 81:538-549.

Nydam, R.L. and Voci, G.E. 2007. Teiid-like scincomorphan lizards from the Late Cretaceous (Campanian) of southern Utah. Journal of Herpetology, 41:211219.

Oppel, M. 1811. Die Ordnungen, Familien und Gattungen der Reptilien, als Prodrom einer Naturgeschichte derselben. Joseph Lindauer, Munich.

Pyron, R.A., Burbrink, F.T., Wiens, J.J. 2013. A phylogeny and revised classification of Squamata, including
4161 species of lizards and snakes. BMC Evolutionary Biology, 13:93: 1-53.

Reynoso, V.H. and Callison, G. 2000. A new scincomorph lizard from the early Cretaceous of Puebla, México. Zoological Journal of the Linnean Society, 130:183-212.

Richter, A. 1994. Die problematische Lacertilier Ilaerdaesaurus (Reptilia; Squamata) aus der Unter-Kreide von Uña and Galve (Spanien). Berliner geowissenschaftliche Abhandlungen, 13:135-161.

Rougier, G.W., Isaji, S., and Manabe, M. 2007. An Early Cretaceous mammal from the Kuwajima Formation (Tetori Group), Japan, and a reassessment of triconodont phylogeny. Annals of the Carnegie Museum, 76:73-115.

Sansom, R.S., Gabbott, S.E., and Purnell, M.A. 2010. Non-random decay of chordate characters causes bias in fossil interpretation. Nature, 463:797-800.

Setoguchi, T., Matsuoka, H., and Matsuda, M. 1999. New discovery of an early Cretaceous tritylodontid (Reptilia, Therapsida) from Japan and the phylogenetic reconstruction of Tritylodontidae based on dental characters, p.117-124. In, Wang, Y. and Deng, T. (eds.), Proceedings of the Seventh Annual Meeting of the Chinese Society of Vertebrate Paleontology. China Ocean Press, Beijing.

Setoguchi, T., Tsubamoto, T., Hanamura, H., and Hachiya, K. 1999. An early Late Cretaceous mammal from Japan, with reconsideration of the evolution of tribosphenic molars. Paleontological Research, 3:1828.

Sha, J. and Hirano, H. 2012. A revised Barremian-Aptian age for the Mitarai Formation (lower Tetori Group, Makito area of central Japan), previously considered Middle Jurassic-earliest Cretaceous. Episodes, 35:431-437.

Shikama, T. 1969. On a Jurassic reptile from Miyamacho, Fukui Prefecture, Japan. Science Reports of Yokohama National University, Section 2, 15:25-34.

Sweetman, S.C. 2009. A new species of the plagiaulacoid multituberculate mammal Eobaatar from the early Cretaceous of southern Britain. Acta Palaeontologica Polonica, 54:373-384.

Sweetman, S.C. and Evans, S.E. 2011. Lissamphibians (frogs, salamanders and albanerpetontids), p.240263. In Batten, D.J. (ed.), Palaeontological Association Field Guide to Fossils, 14. English Wealden fossils. The Palaeontological Association, London.

Takada, T., Matsuoka, H., and Setoguchi, T. 2001. The first multituberculate from Japan, p. 55-58. In Deng, T. and Wang, Y. (eds.), Proceedings of the Eighth Annual Meeting of the Chinese Society of Vertebrate Paleontology. China Ocean Press, Beijing.

Townsend, T.M., Larson, A., Louis, E., and Macey, J.R. 2004. Molecular phylogenetics of Squamata: the position of snakes, amphisbaenians, and dibamids, and the root of the squamate tree. Systematic Biology, 53:735-757. 
Turner, A.H., Hwang, S.H., and Norell, M.A. 2007. A small derived theropod from Öösh, Early Cretaceous, Baykhangor Mongolia. American Museum Novitates, 3551:1-27.

Unwin, D.M., Bakhurina, N.N., Lockley, M.G., Manabe, M., and Lü, J. 1997. Pterosaurs from Asia. Journal of the Palaeontological Society of Korea, 2:43-65.

Unwin, D.M., Manabe, M., Shimizu, K., and Hasegawa, Y. 1996. First record of pterosaurs from the Early Cretaceous Tetori Group: a wing-phalange from the Amagodani Formation in Shokawa, Gifu Prefecture, Japan. Bulletin of the National Science Museum, Tokyo, Series C, Geology and Paleontology, 22:3746.

Unwin, D.M. and Matsuoka, H. 2000. Pterosaurs and birds, p. 51-54. In Matsuoka, H. (ed.), Fossils of the Kuwajima 'Kaseki-kabe' (Fossil-bluff). Scientific Report on a Neocomian (Early Cretaceous) Fossil Assemblage from the Kuwajima Formation, Tetori Group, Shiramine, Ishikawa, Japan. Shiramine Village Board of Education, Ishikawa Prefecture, Japan. (In Japanese)

Vidal, N. and Hedges, S.B. 2009. The molecular evolutionary tree of lizards, snakes, and amphisbaenians. Comptes Rendus Biologie, 332:129-139.

Wang, Y. and Evans, S.E. 2011. A gravid lizard from the Early Cretaceous of China: insights into the history of squamate viviparity. Naturwissenschaften, 98:739743.

Wiens, J.J., Brandley, M.C., and Reeder, T.W. 2006. Why does a trait evolve multiple times within a clade? repeated evolution of snake like body form in squamate reptiles. Evolution, 60:123-141.

Wiens, J.J., Kuczynski, C.A., Townsend, T., Reeder, T.W., Mulcahy, D.G., and Sites, J.W. Jnr. 2010. Combining phylogenomics and fossils in higher-level squamate reptile phylogeny: molecular data change the placement of fossil taxa. Systematic Biology, 59:674-688.

Yabumoto, Y. 2000. Fossil fishes, p.46-49. In Matsuoka, $\mathrm{H}$. (ed.), Fossils of the Kuwajima 'Kaseki-kabe' (Fossil-bluff). Scientific Report on a Neocomian (Early Cretaceous) Fossil Assemblage from the Kuwajima Formation, Tetori Group, Shiramine, Ishikawa, Japan. Shiramine Village Board of Education: Ishikawa Prefecture, Japan. (In Japanese)

Yabumoto, Y. 2014. Sinamia kukurihime, a new Early Cretaceous amiiform fish from Ishikawa, Japan. Paleontological Research, 18: 211-223.

Zanno, L.E. and Makovicky, P.J. 2011. On the earliest record of Cretaceous tyrannosauroids in western North America: implications for an Early Cretaceous Laurasian interchange event. Historical Biology, 23:317-325. 


\section{APPENDIX}

APPENDIX 1. Codings for Kuroyuriella and Asagaolacerta in Gauthier et al. (2012) and Longrich et al. (2012).

Codings in Gauthier et al. (2012) and Longrich et al. (2012) - A=0\&1, B=1\&2; C=2\&3; D=3\&4:

Kuruyuriella $(70.4 \%$ missing data)

0????????? ??????0?0? ?????????? ?????0?1?0 -00-000420

??0000100? ?20?0?C00? ????01???1 ??????01?2 -?00-?A??0

0111-00??? 00?A00?0?0 0?0000001? 0000?????? ??????????

????????0? ?????????? ????????001200?0???? ??????????

????????? ?????????? ???????????????????2?????????

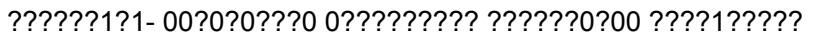

?????????? ?????????? ?????????? ?????????? ??????????

????100001 $400100202000000 ? ? 0 ? 0$ ?0B?101000 0??0-??0?0 0??A0????? ?00-0000D3 3000000000 00?0000??? ?????????? ????????? ?????????? ????????? ?????????? ?????????? ?????????? ?????????- -1??0-0000 0?0??????? ?????????? ????????? 00?0000100 00

Asagaolacerta (85\% missing data)

?????????? ?????????? ?????????? ?????0???? ??????????

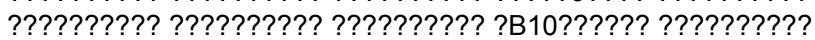

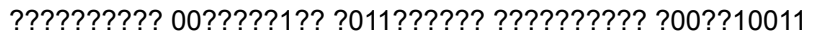
000020?00? ?????????? ??????1?00 1B00?02??? ?????????? ?????????? ?????????? ?????????? ??0?????0? ???0?1- -?? ?????????? ?????????? ?????????? ?????????? ?????????? ?????????? ?????????? ????????? ?????????? ????????? ????1000?1 ????0????? 000000?-?? ?????????? ????????? ?????????? ????0??1?C 2000000000 00?20?0??? ?????????? ????????? ??????11?? ????????? ?????????? ????????? ?????????? ?????????0 000??????? ?????????? ???????001 ????????? ?????????? ?0???????? ?????????? ????????? ?????????? $01 ? 0 ? ? 11000$

APPENDIX 2. Full nexus file of data matrix, see online at palaeo-electronica.org/content/2015/1271-japanese-fossil-lizards 